
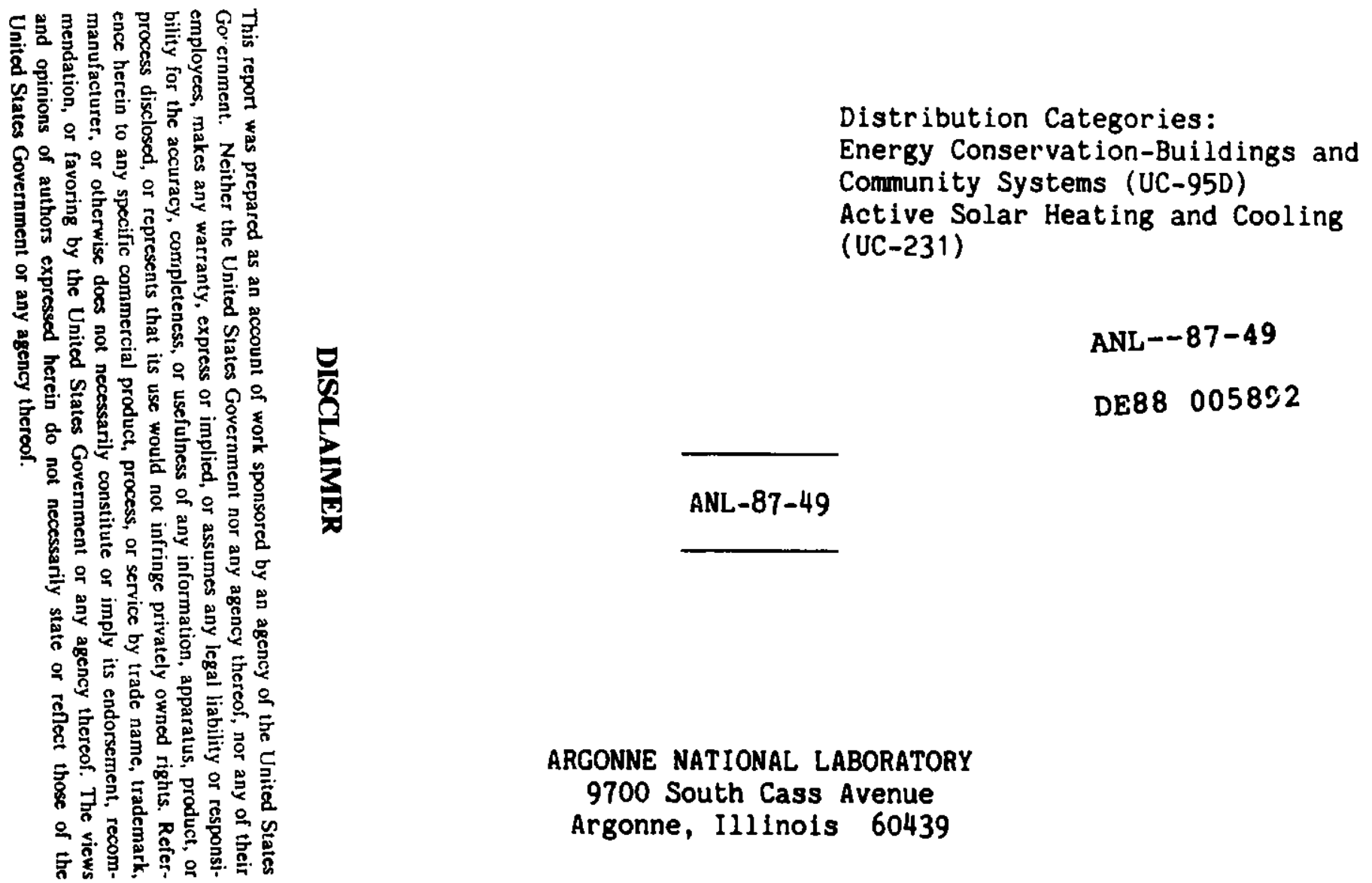

ANL $-87-49$

\author{
ARGONNE NATIONAL LABORATORY \\ 9700 South Cass Avenue \\ Argonne, Illinois 60439
}

\title{
SCREENING AND DEGRADATION TESTS OF LINEAR-POLYMER ADDITIVES FOR DISTRICT HEATING APPLICATIONS*
}

by

U. S. Choi, Y. I. Cho, "* and K. E. Kasza

Materials and Components Technology Division

* Department of Mechanical Engineering and Mechanics

DREXEL UNIVERSITY

Philadelphia, PA 19104

December 1987

Work supported by the U.S. Department of Energy, Conservation and Ren
Energy, Office of Buildings and Community Systems, under Contract W-3 ENG-38. 


\section{LEGBILY}

\section{b.}

1

A major purpose of the Technical Information Center is to provide the broadest dissemination possible of information contained in DOE's Research and Development Reports to business, industry, the academic community, and federal, state and local goveinments.

Although a small portion of this report is not reproducible, it is being made available to expedite the availability of information on the research discussed herein. 


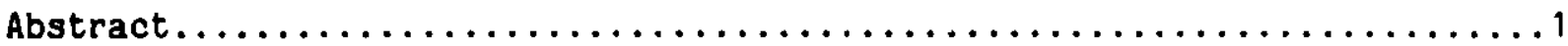

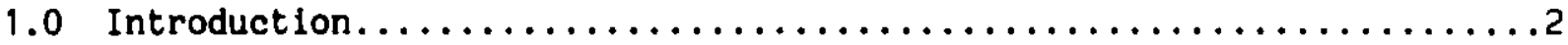

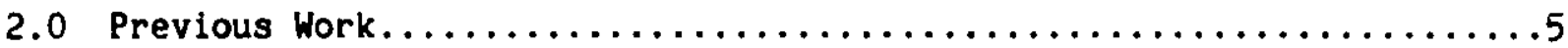

2.1 Hydrodynamic and Heat Transfer Behavior of Viscoelastic

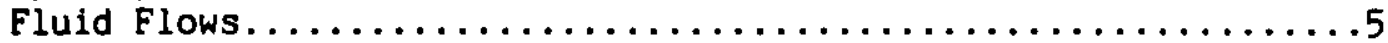

2.2 Degradation of Polymer Solutions.......................

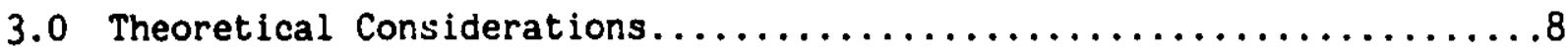

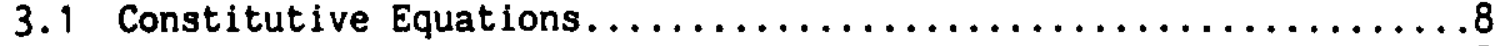

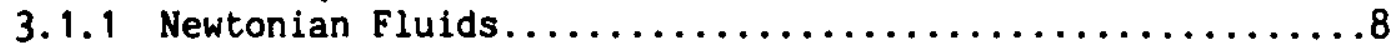

j.1.2 Purely Viscous Time-independent Non-Newtonian Fluids.....9

3.1 .3 Viscoelastic Fluids...........................10

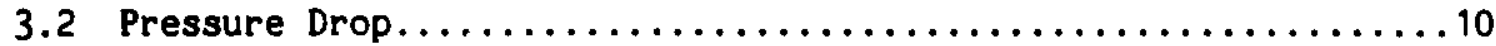

3.2.1 Friction Factor for Newtonian fluids...............11

3.2.2 Friction Factor for Viscoelastic Fluids............12

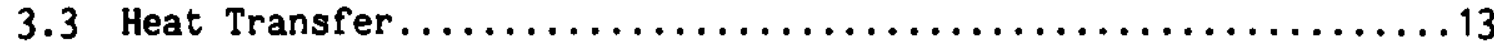

3.3.1 Heat Transfer for Newtonian Fluids.................15

3.3.2 Heat Transfer for Viscoelastic Fluids.............

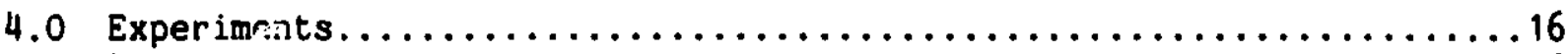

4.1 Experimental Apparatus and Procedures.....................16

4.1 .1 Capillary Tube Viscometer....................... 16

4.1.2 Friction-reducing Additive Degradation Test Loop........17

4.2 Additives Tested and Fluid Properties.....................

5.0 Results and Discussion..........................................

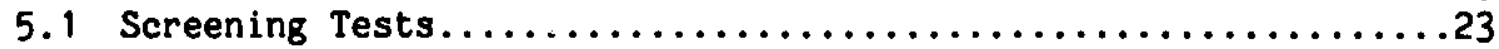

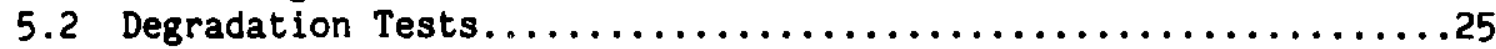

5.2.1 Calibration of the Degradation Test Loop............25

5.2.2 Degradation Tests with Separan Solution.............27

5.2.3 Degradation Tests with Polyox Solution..............33

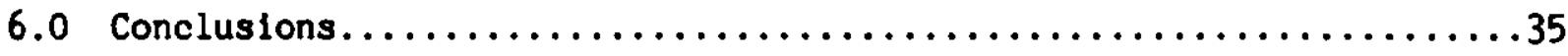

7.0 Future Activities......................................

Acknowledgments........................................... 37

References........................................... 38 
1 Schematic of the Friction-reducing Additive Degradation Test Loop.................................. 18

Pressure Drop and Heat Transfer Test Sections............. 20

3 Percent Friction Reduction vs. Reynolds Number for Polyox

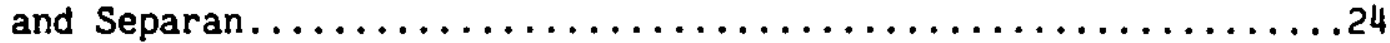

4 Comparison of Percent Friction Reduction for Separan with

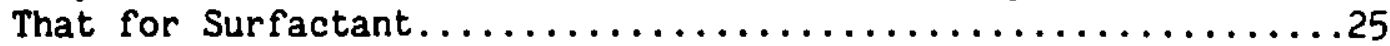

5 Fanning Friction Factor vs. Reynolds Number for Water.......26

6 Nusselt Number vs. Reynolds Number for Water............. 27

$7 \quad$ Pressure Drop and Overall Heat Transfer Coefficient as a Function of Circulation Time for 200 wppm Separan Solution

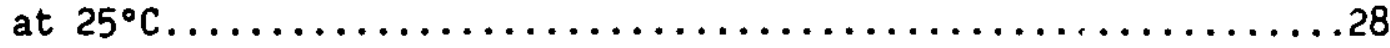

8 Percent Friction/Heat Transfer Reduction Relative to Pure Water as a Function of Circulation Time for

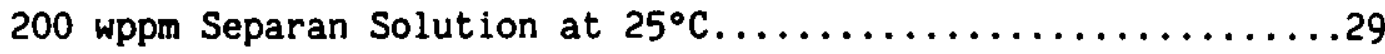

9 Apparent Viscosities of 200 wppm Separan Solution Samples Collected at Different Hours of Shear................. 30

10 The Effect of Temperature on Pressure Drop as a Function of Circulation Time for 200 wppm Separan Solution.............. 31

11 Pressure Drop and Overall Heat Transfer Coefficient as a Function of Circulation Time for 200 wppm Polyox Solution

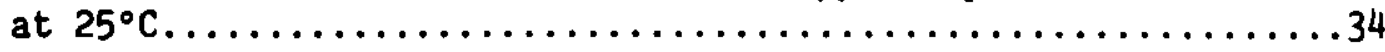

12 Percent Friction/Heat Transfer Reduction Relative to Pure Water as a Function of Circulation Time for 200 wppm Polyox

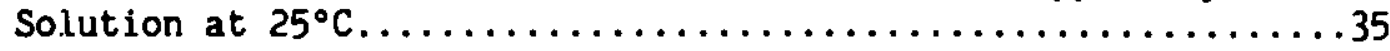

\section{List of Tables}

No.

Properties of Aqueous Linear-Polymer Solutions at the Two Test Temperatures...........................2? 


\begin{tabular}{|c|c|}
\hline$A_{0}$ & Outside surface area of tube \\
\hline$c_{p}$ & Specific heat \\
\hline d & Tube diameter \\
\hline $\mathrm{FR}_{\boldsymbol{q}}$ & Percent friction reduction \\
\hline$f$ & Friction factor \\
\hline $\mathrm{h}$ & Convection heat-transfer coefficient \\
\hline$j_{H}$ & Dimensionless heat transfer $\mathrm{f}$ factor, $\mathrm{St} \cdot \mathrm{Pr}^{2 / 3}$ \\
\hline $\mathbf{K}$ & Flow consistency index \\
\hline k & Thermal conductivity \\
\hline L & Length of tube \\
\hline in & Mass flow rate \\
\hline $\mathbf{n}$ & Power-law index \\
\hline $\mathrm{Nu}$ & Nusselt number defined as $h d / k$ \\
\hline $\operatorname{Pr}$ & Prandtl number defined as $\mathrm{Cp} n / \mathbf{k}$ \\
\hline$q$ & Heat flux \\
\hline $\operatorname{Re}$ & Reynolds number defined as $V d_{\rho} / n$ \\
\hline $\mathrm{Re}_{\mathrm{a}}$ & Reynolds number based on the apparent viscosity \\
\hline St & Stanton number defined as $h / p V C_{p}$ \\
\hline $\mathbf{T}$ & Temperature \\
\hline$u^{*}$ & Friction velocity \\
\hline $\mathrm{U}_{0}$ & Overall heat transfer coefficient \\
\hline V & Mean velocity \\
\hline Ws & Weissenberg number defined as $\lambda V / d$ \\
\hline $\mathrm{Hs}_{\mathbf{f}}$ & Critical Weissenberg number for friction \\
\hline$W s_{h}$ & Critical Weissenberg number for heat transfer \\
\hline$x$ & Axial distance \\
\hline
\end{tabular}


Greek

$\dot{\gamma}$

Shear rate

$\Delta P \quad$ Pressure drop

$\Delta T_{\text {Im }} \quad$ Logarithmic mean temperature difference

$n$

Dynamic viscosity of Newtonian fluid

$\eta_{a} \quad$ Apparent viscosity of non-Newtonian fluid

no Zero shear rate viscosity

n. Infinite shear rate viscosity

Characteristic time of viscoelastic fluid

p Density

$\tau \quad$ Shear stress

\section{Subscripts}

$\begin{array}{ll}\text { a } & \text { Based on the apparent viscosity } \\ \text { b } & \text { Bulk fluid } \\ \text { c } & \text { Cooling water } \\ \text { e } & \text { Entrance region } \\ \text { h } & \text { Hot water } \\ \text { i } & \text { Inlet } \\ \text { m } & \text { Mean } \\ \text { N } & \text { Newtonian } \\ \text { o } & \text { Outlet } \\ \text { p } & \text { Polymer solution } \\ \text { tf } & \text { Test fluid } \\ \text { w } & \text { Evaluated at wall of tube } \\ \text { y } & \text { Yield point }\end{array}$




\section{SCREENING AND DEGRADATION TESTS OF LINEAR-POLYMER ADDITIVES FOR DISTRICT HEATING APPLICATIONS}

by

U. S. Choi, Y. I. Cho, and K. E. Kasza

Abstract

In closed-loop district heating and cooling (DHC) systems, the addition of a friction-reducing additive to the working fluid conveying energy between the energy sources and end users would allow increased load-handling capability (in an existing system) or the use of much smaller pipes and/or pumps (in a new system). As the first step in identifying friction-reducing additives that have a reasonable lifetime at DHC temperatures, two highmolecular-weight linear-polymer additives have been tested at two different temperatures $\left(25.0^{\circ} \mathrm{C}\right.$ and $\left.87.8^{\circ} \mathrm{C}\right)$. The additives are Polyox WSR-301 and Separan AP-273 at 200 wppm in deionized water. Results of capillary tube screening tests with fresh solutions show that both polymers can give more than $60 \%$ friction reduction. However, Separan is effective at high temperatures, whereas Polyox undergoes thermal degradation.

Degradation tests in a closed recirculatory flow system show that (1) friction reduction is always accompanied by heat transfer reduction regardless of the hours of shear, (2) Polyox cannot be used in recirculatory systems because it is very sensitive to mechanical degradation, and (3) although Separan does degrade under high flow shear conditions, it does not degrade completely; it achieves a plateau value of friction reduction even under continuous shear. This is an impurtant discovery and implies that Separan is still a good candidate for closedloop DH systems. 
In order to further explore the suitability of Separan, additional experimental work is needed. In particular, the influence of polymer concentration on degradation needs to be investigated as an approach to improving the plateau value of friction reduction with shear-degraded solutions. Separan must also be evaluated for compatibility with water contaminants and water treatment chemicals. Additionally, Separan is very cheap, and cost comparisons of the substance with other more costly, more robust additives requiring higher concentrations must be conducted. Separan will also be tested at lower temperatures to evaluate its potential for use in DC systems.

\subsection{Introduction}

District heating and cooling (DHC) systems are characterized by long distribution pipes which convey a pumped energy transmission fluid between the source and sink heat exchangers of the systems. These systems operate with small temperature differences, and therefore large volumes of fluid must be pumped and large heat exchangers must be used to satisfy load demands. Improved energy transmission fluids hold promise of improving the performance of existing systems: If the pressure drop or frictional losses associated with pumping these fluids (and hence the pumping power) can be reduced significantly, and the heat transfer occurring at the heat exchangers and tho energy transported per pound of circulating fluid can be increased, operating costs for these systems can be reduced. Also, upfront capital equipment costs can be reduced through the use of smaller pipes, pumps, heat exchangers, and storage tanks in new DHC system designs.

Argonne National Laboratory (ANL), under sponsorship of the U.S. Department of Energy, has been conducting a research program to develop advanced energy transmission fluids for improving DHC system performance. The long-range objectives of the program are as follows: 
1. Identify and develop high-performance thermal-hydraulic energy transmission fluids and components to best utilize these fluids in DHC systems.

2. Demonstrate that the fluids substantially reduce frictional losses and improve heat transfer so that smaller piping, pumps, heat exchangers, and storage tanks can be used. (These benefits will make DHC a more viable and cost-competitive concept.)

3. Generate friction and heat transfer correlations and system performance information needed for design of improved DHC systems.

The efforts to deveiop advanced energy transmission fluids are based on a study which highlighted two concepts that hold considerable promise for improving the performance of DHC systems [1], and on earlier studies associated with the use of phase change slurries as the working fluid in thermal systems in general [2,3]. Both concepts are based on utilizing special additives to DHC energy transmission fluids. The concepts, which can be used separately or combined to achieve maximum benefits, are as follows:

1. Using low concentrations (20 to $200 \mathrm{wppm}$ ) of non-Newtonian additives in an appropriate carrier liquid to reduce frictional turbulent-flow losses.

2. Using a pumpable phase-change slurry, comprising particulates of material with a high heat of fusion conveyed by a liquid, to enhance both bulk convective energy transport and possibly heat transfer coefficients at heat exchanger surfaces. Two examples of candidate particles are ice crystals (for cooling) and crosslinked form-stable high-density polyethylene (for heating).

When the concepts are combined, the advanced energy transmission fluid is made up of the appropriate friction-reducing additive, phase change particles, and carrier liquid.

The present study is focused on the sirst concept, and involves identifying, through carefully controlled screening and degradation experiments, friction-reducing additives suitable for DHC systems. These additives must possess good friction reduction characteristics at low concentrations over the temperature and shear ranges of interest, must have a reasonable lifetime, and must be cost effective. 
Althougn additives are known to be very erfective in friction reduction at room temperature, there is little knowledge of their effectiveness at DHC temperatures. Furthermore, some additives degrade fairly rapidly under recirculatory flow shear. To date, no systematic, carefully controlled experiments have been conducted on friction-reducing additives to characterize friction reduction behavior and compare their tendencies for degradation under practical thermal-hydraulic conditions encountered in DHC systems. Therefore, the main purposes of this study are (1) to screen friction-reducing additives for compatibility with the conditions encountered in DHC distribution systems and for the ability to produce significant reduction in pipe friction losses, and (2) to investigate the effects of mechanical degradation of these additives on turbulent friction and heat transfer performance. Currently, three types of friction-reducing additives are being evaluated for DHC applications:

1. High-Molecular-Weight Linear Polymers

- Polyethylene oxide (Polyox WSR-301)

- Polyacrylamide (Separan AP-273)

2. Surfactants

- Cetyltrimethylammonium salicylate (Tenside)

3. Fibers and Filaments

- Precision-cut polyester fiber

- Prewetted glass fiber

- Iron whisker filaments

High-molecular-weight linear polymers are well known for their significant friction-reducing qualities, and they pose few safety problems. However, they may be susceptible to flow shear degradation, which can result in decreases in friction reduction.

With surfactant or micellar systems, this flow degradation problem can be overcome. The surfactant systems are also subject to mechanical degradation in regions of high shear, but unlike the high polymers, they regain their effectiveness when they come to regions of moderate shear. Therefore, they can be used in a closed recirculatory flow system. The surfactant systems, however, have other limitations. The cationic surfactants are known to be sensitive to chemical contaminants, and some are extremely sensitive to temperature or water chemistry. 
Synthetic fibers may require higher concentrations than polymers or surfactants for a given level of friction reduction. However, suspensions of synthetic fibers have a number of practical advantages over polymers and surfactants. Fibrous solutions offer a much greater resistance to mechanical degradation and can function at both district heating (DH) and district cooling (DC) temperatures. Furthermore, their efficacy is less sensitive to water chemistry and pipe diameter. Also, they can be removed from the fluid, whereas polymers and surfactants cannot.

In this report, our discussion will be limited to work on the first type of additives, i.e., screening and degradation test results for two aqueous linear-polymer solutions at room and high temperatures.

\subsection{Previous Work}

The phenomenon of friction reduction in non-Newtonian fluids was discovered by Toms about 40 years ago [4]. He observed that under conditions of turbulent flow through a circular pipe, aqueous solutions of linear polymers exhibited significant friction reduction relative to the pure solvent (i.e., water). Such friction reduction was found to be associated with the suppression of fluctuating eddies by the long-chain molecules. Subsequently, the hydrodynamic and heat transfer behavior of non-Newtonian fluids in turbulent pipe flow has been extensively investigated owing to the potential application and associated benefits of the friction reduction phenomenon when a large quantity of fluid is transported over a long distance. A number of books [5-8] and review articles [9-17] discuss the friction and heat transfer behavior of various non-Newtonian fluid flows. Turbulent-flow cases that are relevant to the present study are briefly discussed below.

\subsection{Hydrodynamic and Heat Transfer Behavior of Viscoelastic Fluid Flows}

The hydrodynamic and heat transfer behavior of viscoelastic fluids in turbulent pipe flow is quite different from that of Newtonian fluids or purely viscous non-Newtonian fluids. The friction and heat transfer coefficients of viscoelastic fluids in turbulent flows were observed to be substantially lower than the values associated with pure 
solvent water (i.e., Newtonian fluid) or purely viscous non-Newtonian fluids [16]. In general, the percentage friction and heat transfer reductions in a turbulent channel flow depend on flow rate, additive type, and additive concentration. In addition, the pipe diameter $d$, the degree of polymer degradation, and the solvent chemistry were found to be important parameters in the determination of the amount of friction and heat transfer reductions.

It should be noted, however, that the friction and heat transfer reductions are ultimately limited by unique asymptotes which are independent of the polymer concentration, solvent chemistry, and degree of degradation. The asymptotes are solely dependent on the Reynolds number and dimensionless axial distance $x / d$. For both hydrodynamically and thermally fully developed turbulent flows, the maximum friction and heat transfer reduction asymptotes are a function of only one parameter, the Reynolds number based on the apparent viscosity. The percentage friction and heat transfer reductions for the asymptotes, which increase with Reynolds number, lie in the range of $60-80 \%$.

In the intermediate range (i.e., between Newtonian and the minimum asymptotic values), the above-mentioned parameters such as polymer concentration, solvent chemistry, pipe diameter, and degradation of polymer solutions were found to play important roles in the determination of turbulent friction and heat transfer coefficients. Recently, another dimensionless number, Ws, called the Weissenberg number, has been used to take into account the effects of these parameters on the turbulent friction and heat transfer performance $[17-19]$. Of note is that since a viscoelastic fluid has a characteristic time in its constitutive equation, an additional dimensionless number would be required to correlate experimental data, as can be shown from the analysis of the Buckingham $\mathrm{Pi}$ theorem. In operational terms, the fully established turbulent friction and heat transfer coefficients can be written as

$$
\begin{array}{ll}
f=f\left(R e_{a}, W s\right) & \text { for } W s<W s_{f}, \\
j_{H}=J_{H}\left(R e_{a}, W s\right) & \text { for } W s<W s_{h},
\end{array}
$$


where $f$ is the Fanning friction factor, $j_{H}$ the heat transfer $f$ factor, and $\mathrm{Re}_{\mathrm{a}}$ the Reynolds number based on the apparent viscosity (see SEc. 3.2.2 below). The Weissenberg number $W$ is defined as $\lambda V / d$, which is the ratio of the characteristic time of fluid $\lambda$ to the characteristic time of flow $\mathrm{d} / \mathrm{V}$. Also, $\mathrm{Ws}_{\mathrm{f}}$ and $W \mathrm{~s}_{\mathrm{h}}$ are the critical Weissenberg numbers for friction and heat transfer corresponding to the minimum asymptotes, respectively. Equations 2.1 and 2.2 indicate thai when the Weissenberg number is less than the corresponding critical number, the turbulent friction and heat transfer soefficients will depend on both the Reynolds and Weisse!.oerg numbers. On the other hand, when the Weissenberg number is greater than the corresponding critical Weissenberg number, the friction or heat transfer results become functions of the Reynolds number only, reducing to the respective minimum asymptote. In general, the critical Weissenbers numbers for friction and heat transfer were observed to be 5-10 and 200250 , respectively $[18,19]$, based on the characteristic time calculated from the Powell-Eyring model [20].

\subsection{Degradation of Polymer Solutions}

When aqueous solutions of high-molecular-weight polymers are recirculated in a closed loop system, the polymer networks are continuously ruptured, thus decreasing the average or effective molecular weight of the polywer solutions. The effect of such mechanical degradation on rheological properties of polymer solutions becomes an important issue when one wants to use friction-reducing additives in practical engineering systems. In general, shear degradation results in simultaneous decreases in the normal force difference, low-shear-rate viscosity (at shear rates of 0.1 to $10 \mathrm{~s}^{-1}$ ), and characteristic time of polymer solutions. However, the viscosity at high shear rates (700 to $\left.9,000 \mathrm{~s}^{-1}\right)$ remains unchanged, whereas the low-shear-rate viscosity is changed by a factor of 10-100.

Effects of mechanical degradation on the friction and heat transfer performance of friction-reducing viscoelastic fluids have been studled by a number of investigators [21-25]. Tung et al. [24] conducted degradation test.s with Separan solution (2500 wppm in tap water) for 552 hours of continuous shear at room temperature. The friction coefficient stayed essentially unchanged for up to 500 hours before it began to 
increase gradually. However, heat transfer was not measured. Later, $\mathrm{Ng}$ et al. [25] conducted degradation tests by continuously circulating Separan solution ( $1500 \mathrm{wppm}$ ) for 72 hours and subsequently reported friction and heat transfer data. They found that the heat transfer process was more sensitive to mechanical degradation than the pressure drop. Cho and Hartnett [16] observed that aqueous solutions of Polyox were more susceptible tc shear degradation than solutions of Separan. However, these tests $[16,24,25]$ were conducted on polymer solutions at relative?y high concentrations, well beyond the current intended application of such fluids in DH systems. Therefore, in the present degradation tests, dilute polymer solutions of $200 \mathrm{wppm}$ were used to investigate the long-term effectiveness of friction-reducing additives in room and higher temperature environments.

The friction velocity, $u^{*}$, below which degradation would not take place was reported to be approximately $10 \mathrm{~cm} / \mathrm{s}(0.33 \mathrm{ft} / \mathrm{s}$ ) for Polyox (WSR$301)$ and $30 \mathrm{~cm} / \mathrm{s}(0.98 \mathrm{ft} / \mathrm{s})$ for Separan (AP-30) [23]. However, these limiting values of $u^{*}$ did not take into account the mechanical degradation occurring in pump and pipe fittings such as elbows, branches, and sharp entrance edges, and thus the overall degradation in a closed recirculatory flow system was underestimated.

\subsection{Theoretical Considerations}

The definitions and equations used for the computation and discussion of the experimental results are reviewed in this chapter.

\subsection{Constitutive Equations}

\subsubsection{Newtonian Fluids}

Newtonian fluids are characterized by the simple constitutive (or rheological) equation

$$
\tau=\dot{n} \dot{\gamma}
$$

where $\tau$ is the shear stress, $n$ the dynamic viscosity, and $\dot{\gamma}$ the shear rate. The viscosity is constailt at any given temperature and pressure and is independent of time and shear rate. Therefore, this single property 
defines the rheological behavior of Newtonian fluids. Examples of Newtonian fluids include all gases and water.

\subsubsection{Purely Viscous Time-independent Non-Newtonian Fluids}

The viscosity of a purely viscous time-independent nonNewtonian fluid can be a function of the shear rate. A simple type of shear rate dependency is the power law (or Ostwald de Waele) model:

$$
\tau=K \ddot{r}^{n}
$$

where $\mathrm{K}$ is the flow consistency index and $\mathrm{n}$ is the power-law index (or flow behavior index), which is a measure of the non-Newtonian character of the fluid. For pseudoplastic fluids, $n<1$; for dilatant fluids, $n>1$; and for Newtonian fluids, $n=1$. In general, $K$ and $n$ are themselves dependent on the shear rate.

When Eq. (3.2) is modified so as to have the same formal structure as the classical expression (Eq. 3.1), it can be written as

$$
\tau=\left(K \dot{r}^{n-1}\right) \dot{\gamma}
$$

this gives an apparent viscosity of

$$
n_{a}=k \dot{r}^{n-1}
$$

which clearly shows the dependency of the viscosity on the shear rate.

$$
\text { Bingham flulds may be represented by this power-law model }
$$

if Eq. (3.3) is modified to account for the fact that the Bingham sluid exhibits a definite yield stress at zero shear rate. This gives the following expression:

$$
\tau=\tau_{y}+\left(K \dot{\gamma}^{n-1}\right) \dot{\gamma}=\left(\frac{\tau}{\dot{y}}+K \dot{\gamma}^{n-i}\right) \dot{\gamma},
$$

where $\tau_{y}$ is the yield stress. Then, the apparent viscosity of the Bingham fluid is 


$$
\eta_{a}=\frac{\tau y}{\dot{\gamma}}+K \dot{\gamma}^{n-1} .
$$

\subsubsection{Viscoelastic Fluids}

Although a large number of differential or integral constitutive equations have been developed for viscoelastic materials (see Refs. 6, 26, and 27 for discussions of the various types and characteristics of proposed complex constitutive equations), these models are complicated. On the other hand, there are a number of relatively simple empirical constitutive equations which are useful to us in our study of pipe flow problems. The Powell-Eyring equation is

$$
\eta=n_{\infty}+\left(n_{0}-n_{\infty}\right)\left(\sinh ^{-1} \lambda \dot{\gamma}\right) / \lambda \dot{\gamma},
$$

and the Carreau equation is

$$
n=n_{\infty}+\left(n_{0}-n_{\infty}\right)\left[1+(\lambda \dot{r})^{2}\right]^{(n-1) / 2},
$$

where $n_{\infty}$ is the infinite shear rate viscosity and $n_{0}$ is the zero shear rate viscosity. If the characteristic time $\lambda$ is known, nondimensional numbers (such as the Weissenberg or Deborah numbers) can be computed to provide an additional parameter for a better description of the flow of the viscoelastic fluid.

Some of the most commonly studied viscoelastic fluids are polymer solutions, which often present a viscosity function consisting of Newtonian regions at low and high shear rates and a pseudoplastic region for intermediate shear rates.

\subsection{Pressure Drop}

In the pipe flow of a Newtonian or non-Newtonian fluid, the commonly used relationship between the pressure drop and the mean velocity is expressed in terms of the Fanning friction factor, defined as

$$
f=\frac{\tau}{\frac{\tau}{2} \rho v^{2}}=\frac{d}{2 \rho v^{2}} \frac{\Delta P}{L}
$$


where $\Delta \mathrm{P}$ is the pressure drop over a length of the tube $\mathrm{L}$, $d$ the tube diameter, $\rho$ the density of the fluid, and $V$ the mean velocity over a cross section of the tube. The friction factor is essentially a dimensionless pressure gradient, and it is a function of the Reynolds number for fully developed flow of Newtonian fluids.

In order to obtain fully established friction factors it is essential to measure the pressure drop between two pressure taps in the fully developed flow region. The entrance length $L_{e}$ for laminar flow of Newtonian fluids is given by Kays and Crawford [28] as

$$
\frac{L_{e}}{d}=\frac{R e}{20} \text {. }
$$

The maximum value of $L_{e}$ would be about 100 diameters for the case of laminar flow. The hydrodynamic entrance region for turbulent flows of Newtonian fluids is fairly short, and 20 diameters are usually sufficient. However, for non-Newtonian fluids, $\mathrm{L}_{e}$ is approximately 100 diameters [16]. For this reason, the pressure drop was measured at $x / d>196$ for all solutions in the present study.

\subsubsection{Friction Factor for Newtonian Fluids}

In the fuliy developed laminar flow regime, the friction

factor is simply

$$
f=\frac{16}{\operatorname{Re}}
$$

where $R e$ is the Reynolds number, defined as

$$
R e=\frac{\rho V d}{n} .
$$

For fully developed turbulent flows, the Von Karman relation for Newtonian fluids is used in this study, i.e.,

$$
1 / J f_{N}=1.74 \ln \left(\operatorname{Re} / f_{N}\right)-0.40
$$

for $3 \times 10^{3}<\operatorname{Re}<3 \times 10^{6}$. 
The Blasius equation is also used:

$$
f_{N}=0.079 R e^{-0.25}
$$

The Blasius friction formula is as accurate as the logarithmic formula, Eq. (3.13), and is within 2\% of the experimental data for $\operatorname{Re}<10^{5}[29]$.

\subsubsection{Friction Factor for Viscoelastic Fluids}

In the presentation of experimental results describing the fluid mechanics and heat transfer behavior of non-Newtonian fluids flowing through circular tubes, at least five different definitions of the Reynolds number have been used by various investigators [16]. In the present study, a Reynolds number based on the apparent viscosity at the wall, $\eta_{a}$, will be used for viscoelastic fluids. Thus,

$$
\mathrm{Re}_{\mathrm{a}}=\frac{\mathrm{eVd}}{n_{\mathrm{a}}} \text {. }
$$

This approach is more adequate than other definitions because it is believed that the friction reduction phenomenon uccurs very close to the wall.

The wall shear in laminar tube flow is

$$
\tau_{w}=n_{a} \frac{3 n+1}{4 n} \frac{8 v}{d} .
$$

Thus, the laminar friction factor for a viscoelastic fluid is

$$
f=\frac{3 n+1}{4 n} \frac{16}{\operatorname{Re}_{a}}
$$

which is now a function of $n$ as well as $\mathrm{Re}_{\mathrm{a}}$.

In turbulent flow, the friction factor for a viscoelastic fluid may be significantly smaller than for a Newtonian fluid. In the limiting case of Virk's maximum friction reduction asymptote, the friction factor is given as [30] 


$$
\frac{1}{\sqrt{f}}=19.0 \log \left(\operatorname{Re}_{a} / f\right)-32.4
$$

Cho and Hartnett proposed the following empirical

correlation [16], which is easier to use than Eq. (3.18):

$$
f=0.20 \operatorname{Re}_{\mathrm{a}}-0.48
$$

for $6000<\operatorname{Re}_{a}<60000$. This correlation leads to friction factors that are lower than Virk's by 6-20\%.

These friction factor expressions indicate that for the maximum friction reduction asymptote case, the friction factor is independent of the type of polyiner and solvent used. However, for cases that do not correspond to asymptotic conditions, the friction curve will be located somewhere between the Newtonian curve and the Virk's asymptote and will be a function of additive and solvert type and concentration.

\subsection{Heat Transfer}

In tube flow, the convection heat-transfer coefficient $h$ is usually defined by

$$
h=\frac{q_{w}}{T_{w}-T_{b}}
$$

where $q_{W}$ is the wall heat flux, $T_{W}$ the wall temperature, and $T_{b}$ the bulk fluid temperature. Then the Nusselt number is defined as

$$
\text { Nu }=\frac{\text { hd }}{k} \text {, }
$$

where $k$ is the thermal conductivity of the fluid.

For Newtonian fluids, the thermal entrance length required to obtain a hydrodynamically and thermally fully developed value of Nu in a laminar pipe flow is given by [28]

$$
\frac{L_{e}}{d}=0.05 \operatorname{Re} \mathrm{Pr} .
$$


For $\operatorname{Re}=2000$ and $\operatorname{Pr}=6$, the thermal entrance length would be 600 diameters. However, for turbulent flow, the entrance lengths are shorter and for $\mathrm{Pr}>5,20$ diameters should be sufficient for the local $\mathrm{Nu}$ to approach its fully developed value. For viscoelastic fluids, very large thermal entrance lengths are required in turbulent flow. $\mathrm{Ng}$, Cho, and Hartnett [31] found that the thermal entrance length increases with increasing polymer concentration, extending to 430 diameters for 1000 wppm Separan solution.

In a double-tube heat exchanger as used in the heat-transfer test section of the degradation test loop in the current study, the overall heat transfer by combined conduction and convection would be expressed in terms of an overall heat transfer coefficient $U_{0}$, defined by the relation

$$
U_{0}=q_{W} / A_{0} \Delta T_{1 m}
$$

where $q_{W}$ is the heat exchanger heat load, $A_{0}$ is the outside surface area of the inner pipe, and $\Delta \mathrm{T}_{\mathrm{lm}}$ is the logarithmic mean temperature difference.

When the inlet and outlet temperatures and flow rates of the hot and cold fluids are measured, the total heat transferred from hot fluid to cold fluid can be calculated from

$$
q_{w}=\dot{m}_{h} C_{p h}\left(T_{h i}-T_{h o}\right)=\dot{m}_{c} C_{p c}\left(T_{c o}-T_{c i}\right)
$$

and

$$
\Delta T_{l m}=\frac{\left(T_{h o}-T_{c i}\right)-\left(T_{h i}-T_{c o}\right)}{\ln \left[\left(T_{h o}-T_{c i}\right) /\left(T_{h i}-T_{c o}\right)\right]} .
$$

When the temperature difference between the hot and cold fluids does not vary along the axis of the heat exchanger, the overall heat transfer coefficient can be obtained from

$$
U_{0}=q_{w} / A_{0}\left(T_{h i}-T_{c o}\right)
$$




\subsubsection{Heat Transfer for Newtonian Fluids}

In a fully developed laminar flow, the local Nusselt

number is given for the constant-heat-flux boundary condition by

$$
\mathrm{Nu}_{\infty}=4.364,
$$

with the usual assumptions of no axial heat conduction and no viscous dissipation.

For fully developed turbulent flow in smooth tubes, the relation recommended by Dittus and Boelter [32] is used:

$$
\mathrm{Nu}=0.023 \mathrm{Re}^{0.8} \operatorname{Pr}^{\mathrm{n}}
$$

The properties in this equation are evaluated at the fluid bulk temperature, and the value of the exponent $n$ is 0.4 for heating and 0.3 for cooling.

\subsubsection{Heat Transfer for Viscoelastic Fluids}

For fully developed laminar flow with the constant-heatflux boundary condition, the Nusselt number can be expressed as $[7,16]$

$$
N u=\frac{8(3 n+1)(5 n+1)}{31 n^{2}+12 n+1}
$$

For fully developed turbulent flow, Cho and Hartnett [16] developed the following correlation for the maximum heat transfer reduction asymptote for $4000<\mathrm{Re}_{\mathrm{a}}<40000$ :

$$
J_{H}\left(=S t \operatorname{Pr}^{2 / 3}\right)=0.03 \operatorname{Re}_{a^{-0.45}}
$$

where St is the Stanton number $\left(=\frac{h}{\rho V C_{p}}\right)$ and $\operatorname{Pr}$ is the Prandtl number
$\left(=\frac{C p \eta}{h}\right)$. $\left(=\frac{C p \eta}{k}\right)$. 


\subsection{Experiments}

\subsection{Experinental Apparatus and Procedures}

Screening is being done on two systems. A capillary tube system is used for preliminary screening of fresh solutions. In the first stage of the screening process, the friction-reducing additives that are effective at DHC temperatures are chosen from among a number of additive candidates. Also, the additive concentration corresponding to the maximum friction reduction asymptote is identified. Then, the most effective additives chosen from preliminary capillary tube screening go through longterm degradation tests in the ANL friction-reducing additive degradation test loop, described below. This final screening is needed because preliminary screening involves only fresh solutions and tells us nothing about the practical longevity of an additive solution.

\subsubsection{Capillary Tube Viscometer}

The ANL-fabricated capillary tube viscometer provides fast and precise measurements of turbulent frictional pressure drop as well as rheological properties. A cylindrical pressure vessel of $10.2 \mathrm{~cm}$ (4.0 in.) Inside diameter and $26 \mathrm{~cm}$ (10.24 in.) length, designed for a maximum working pressure of $3310 \mathrm{kPa}$ ( $480 \mathrm{psia}$ ), is used as a test fluid reservoir. The reservoir tank is charged with test fluid and is pressurized by compressed nitrogen. The test fluid is forced to flow through a long smooth capillary tube of known dimensions. The actual pressure within the reservoir is measured by a transducer with a very high accuracy and a Heise pressure gauge. The test fluid flow rate is measured with a bucket and stopwatch. A high-precision pressure regulator maintains a constant reservoir pressure, even at high flow rates. The apparent viscosity and the percent friction reduction are calculated from the measured values of pressure and flow rate.

The instrument's construction permits a wide range of capillary tube dimensions (length and diameter) to be used. However, selection of those dimensions depends on the test fluid's viscosity and desired shear rate. The capillary tube used for screening linear-polymer solutions had an inside diameter of $0.1022 \mathrm{~cm}(0.0402$ in.) and a length of $60.484 \mathrm{~cm}$ (23.82 in.); thus, $\mathrm{L} / \mathrm{d}=591.8$. 
Detailed discussions on the theoretical background for non-Newtonian fluid flow through a capillary tube can be found in the book by Skelland [5].

\subsubsection{Friction-reducing Additive Degradation Test Loop}

DHC systems are closed systems in which working-fluid recirculation is used to transport thermal energy. Although some additives chosen from preliminary screening with the capillary tube system or in once-through or short-term pipe flow tests are very effective in friction reduction, they may degrade when sheared under prototypic conditions for an extended period of time. Therefore, friction-reducing additives must be subjected to long-term recirculation flow degradation testing under prototypic shear conditions to assess their potential for DHC applications.

The ANL friction-reducing additive degradation test loop is a closed recirculatory flow system. A schematic diagram of the experimental apparatus is shown in Fig. 1. It consists of a reservoir tank, a pump, a bypass valve, a surge tank, a calming section, a hydrodynamic entry section, a pressure drop and heat transfer test section, a heat exchanger, a turbine flow meter, a fluid collection apparatus for measuring and calibrating flow rates, and a flow-return system. In addition, a thermostat-controlled heater/chiller and a 5-kW immersion heater allow operation with the recirculatory solutions at temperatures between $7^{\circ} \mathrm{C}\left(45^{\circ} \mathrm{F}\right)$ and $93^{\circ} \mathrm{C}\left(200^{\circ} \mathrm{F}\right)$.

In this study, a tubing pump was used so that the additive degradation would be caused dominantly by the wall shear stresses along the length of the test section rather than in the pump. To reduce the effect of pumping head pulsations on the differential pressure measurements, a surge tank was installed between the pump and the inlet of the pressure drop measurement test section.

Since the hydrodynamic and thermal entrance lengths were found to be approximately 110 and 450 pipe diameters, respectively [16], a long test section with a length-to-diameter ratio $(x / d)$ of 826 was used to obtain friction and heat transfer coefficients in fully developed turbulent 


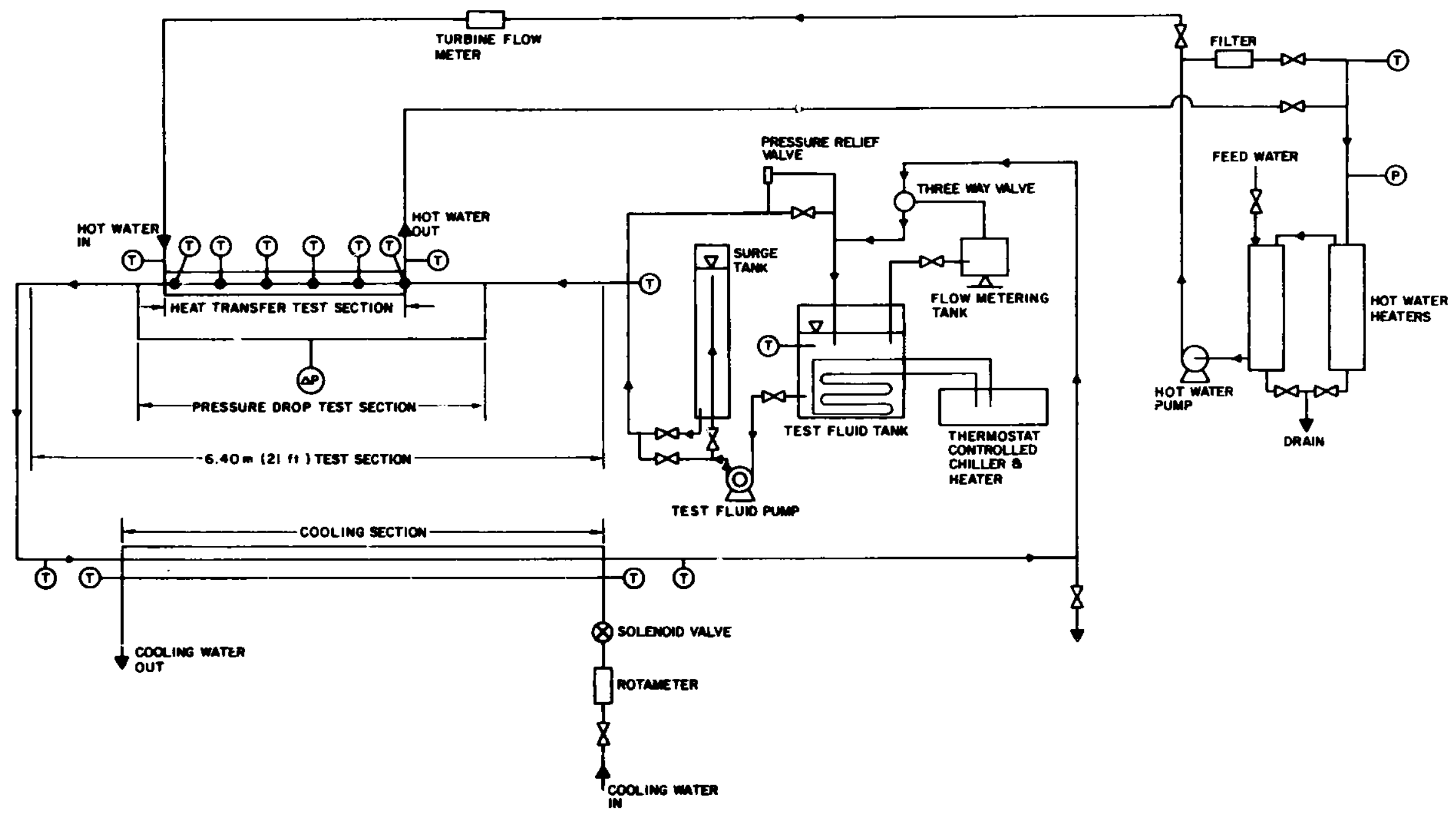

Fig. 1. Schematic of the Friction-reducing Additive Degradation Test Loop. 
flow. The main test section is a straight tube of $0.7747 \mathrm{~cm}(0.305 \mathrm{in.})$ inside diameter and $6.4 \mathrm{~m}(2 \% \mathrm{ft})$ length in which both pressure drop and heat transfer are measured as a function of circulation time (see Fig. 2 for a detailed schematic of the test sections).

For the differential pressure drop measurements, three pressure taps were irstalled along the pipe axial direction. At each pressure tap location, three 2.38-mm (3/32-in.) holes were drilled perpendicular to the axis of the pipe. Several different shapes of scrapers were used to remove burrs from the drilled holes. The adapter collars for the pressure tap holes were made of Teflon to minimize heat conduction loss from the test section and at the same time to average pressure readings circumferentially. Valves were connected to the fittings at the top and bottom of each adapter collar. The valves on the top were used to bleed any entrapped air bubbles. The valves at the bottom were connected by means of heavy-wall vinyl plastic tubing to the pressure transducer for differential pressure measurements. Differential pressure was measured in the fully developed flow region by using pressure taps 2 and 3 , which were separated by $4.27 \mathrm{~m}(14 \mathrm{ft})$. The supplemental instruments included a pressure transducer system (by Sensotec) for differential pressure drop measurements, which were recorded by a Fluke Model 2285B Data Logger.

A concentric-pipe heat transfer test section, simulating actual counterflow heat exchanger operation, was fabricated to measure the turbulent heat transfer coefficient. The length of this section was $3.66 \mathrm{~m}$ $(12 \mathrm{ft})$. The inner tube was made of seamless stainless steel tube of $0.7747 \mathrm{~cm}$ (0.305 in.) inside diameter. The outer concentric tube, of $1.3868 \mathrm{~cm}$ (0.546 in.) inside diameter, was made of CPVC for hightemperature application. Water was supplied to the annular section in a reverse direction so that the heat exchange between aqueous polymer solution and water took place in a counter flow mode.

The heat transfer test section was preceded by a 2-m-long hydrodynamic development section. Thus, the hydrodynamically fully developed flow could be obtained at the inlet of the heat transfer test section. Heat added to the test fluid was removed in the cooling section 


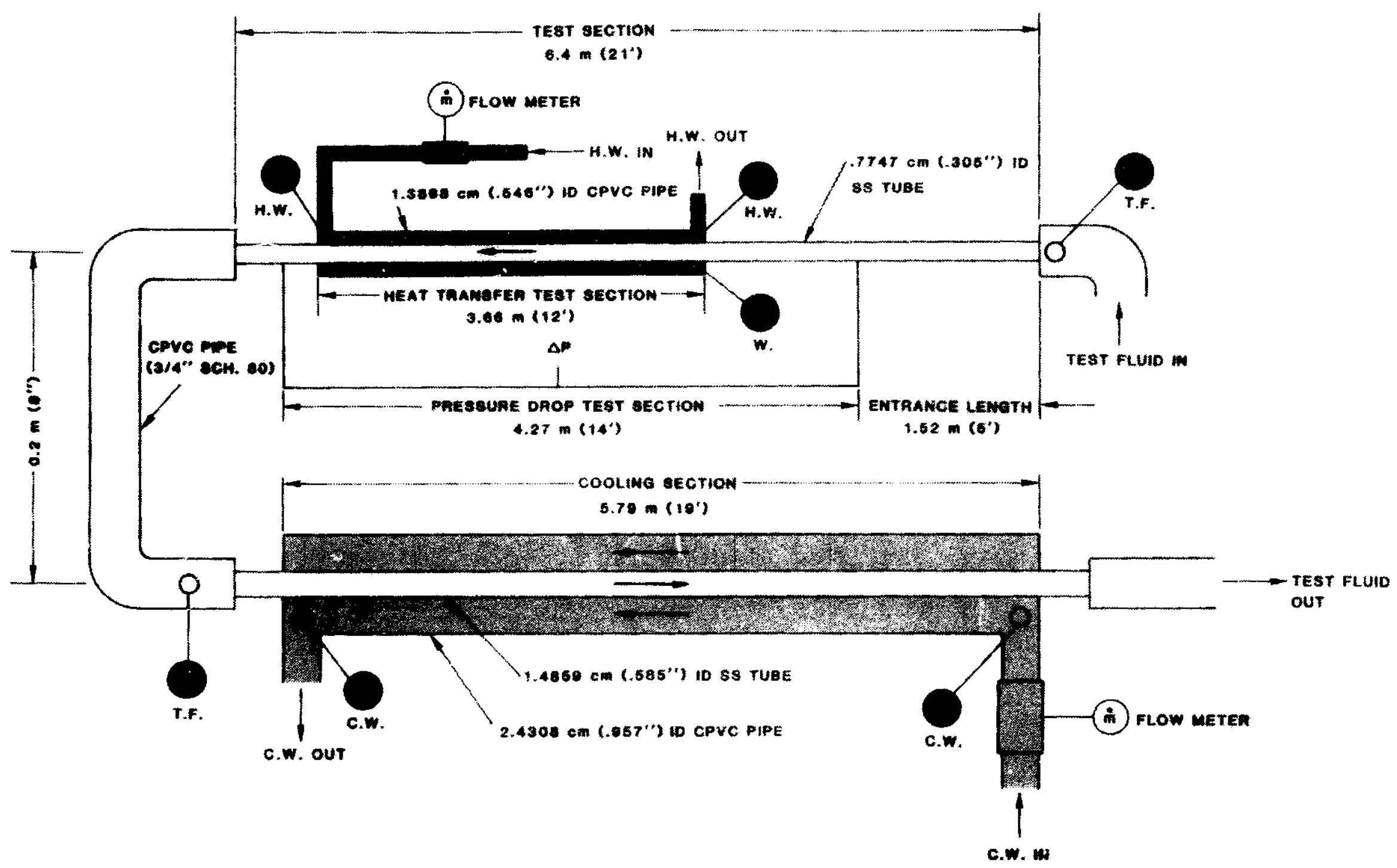

Fig. 2. Pressure Drop and Heat Transfer Test Sections. 
shown in the lower halves of Figs. 1 and 2. The amount of cooling water was automatically controlled by a cooling-water control valve, which was opened by a feedback signal from a thermostat monitoring the test fluid temperature. Thus, prior to entering the main reservoir tank for recirculation, the test fluid was maintained at a constant temperature throughout the period of the heat transfer test. When the test fluid temperature was higher than the hot-water temperature in the heat transfer test section, the heat removed from the test fluid was compensated by a 5$\mathrm{kW}$ immersion heater in the test fluid tank. The inlet and outlet temperatures of the test fiuid and those of the hot or cooling water were measured by thermocouples in the flows.

Thermucouples made from 30-gauge copper-constantan (Type T) were cemented with a high-thermal-conductivity epoxy (A66 1 by Armstrong Products Co.) along the length of the heat transfer test section. Six thermocouples were installed on the outside wall of the test section to measure the local outside wall temperatures. The locations of the thermocouples are at $x / d=0,120,240,340,400$, and 460. Each thermocouple wire was securely tied to the test tube. The thermocouple data were recorded on the Fluke Data Logger. From the outside-wall temperature data, the corresponding inner-wall temperature was calculated by using the thermal conductivity value of stainless steel.

Flow rates of hot and cooling water were measured by using a turbine flow meter and rotameter, respectively. The output of the turbine flow meter was automatically recorded on the Fluke Data Logger whenever temperature readings were made. The mass flow rate of the main test fluid was measured by collecting fluid samples over a short period of time (typically one minute) and weighing them with a precision digital balance.

\subsection{Additives Tested and Fluid Properties}

Two high-molecular-weight linear polymers, Polyox WSR-301 (polyethylene oxide, supplied by Union Carbide) and Separan AP-273 (polyacrylamide, supplied by Dow Chemical), were tested at a concentration of 200 wppm in deionized water. For a DH system, information on additive 
performance at room temperature as well as elevated temperature is important because the systems under start-up conditions may not be "hot," and if a friction-reducing additive is ineffective at the lower temperature the pumps may not be adequate to achieve start-up conditions. Therefore, tests were conducted at both $25^{\circ} \mathrm{C}\left(77^{\circ} \mathrm{F}\right)$ and $87.8^{\circ} \mathrm{C}\left(190^{\circ} \mathrm{F}\right)$.

At the low concentrations used in this study, the additives did not significantly modify the density, thermal conductivity, and specific heat capacity of the water solvent. However, the addition of a small amount of linear-polymer additive significantly increased the viscosity of the fluid, particularly at low shear rates. Nonetheless, a substantial reduction in turbulent-flow pressure drop resulted. The apparent viscosity of the aqueous linear-polymer solutions was measured with the capillary tube viscometer. The use of this apparent viscosity allows the development of adequate correlations for the friction and heat transfer results [for example, see Eqs. (3.19) and (3.30)]. Properties of the tested solutions are listed in Table 1 for room and elevated temperature along with the properties of water for comparison.

Table 1. Properties of Aqueous Linear-Polymer Solutions ${ }^{\mathrm{a}}$ at the Two Test Temperatures

Test Fluid

\begin{tabular}{|c|c|c|c|c|c|}
\hline Polyox & Solution & Separan & Solution & & er \\
\hline $25^{\circ} \mathrm{C}$ & $87.8^{\circ} \mathrm{C}$ & $25^{\circ} \mathrm{C}$ & $87.8^{\circ} \mathrm{C}$ & $25^{\circ} \mathrm{C}$ & $87.8^{\circ} \mathrm{C}$ \\
\hline 62.18 & 60.59 & 62.18 & 60.81 & 62.18 & 60.35 \\
\hline 0.352 & 0.390 & 0.352 & 0.390 & 0.352 & 0.390 \\
\hline 0.998 & 1.003 & 0.998 & 1.003 & 0.998 & 1.003 \\
\hline 1.164 & 0.424 & 2.119 & 1.418 & 1.000 & 0.364 \\
\hline 1.111 & 0.424 & 1.637 & 0.976 & 1.00 & 0.364 \\
\hline 0.97 & 1.0 & 0.841 & 0.820 & 1.0 & 1.0 \\
\hline
\end{tabular}

$a_{200}$ wppm. 


\subsection{Results and Discussion}

\subsection{Screening Tests}

The pressure drop of the fresh polymer solutions at $200 \mathrm{wppm}$ concentration in turbulent flow through the capillary tube was measured for a wide range of mass flow rates, and temperatures of $25.0^{\circ} \mathrm{C}$ and $87.8^{\circ} \mathrm{C}$. From these measurements, the Fanning friction factor for a polymer solution was calculated as follows:

$$
f_{p}=\frac{\pi^{2} d^{5} \rho \Delta p}{32 L \dot{m}^{2}}
$$

where $d$ is the internal diameter of the capillary tube, $p$ the density of the test fluid, $\Delta P$ the measured turbulent pressure drop, $L$ the length of the capillary tube, and $\dot{m}$ the flow rate of the test fluid.

In computing the percent friction reduction, the friction factor relations for Newtonian fluids, Eqs. (3.13) and (3.14), were used as a baseline; i.e., the percent friction reduction was defined as

$$
F R_{y}=\frac{f_{N}-f_{p}}{f_{N}} \times 100 .
$$

The $\mathrm{FR}_{\mathrm{q}}$ results are shown in Fig. 3 in terms of the apparent Reynolds number. The Virk's maximum friction reduction for viscoelastic fluids in a fully developed channel flow is also shown for comparison. The results for the 200 wppm Separan solution show that Separan is an effective friction-reducing additive over the temperature range of $25-87.8^{\circ} \mathrm{C}$ with the maximum friction reduction in the neighborhood of $80 \%$, which corresponds to Virk's maximum value. The data for the 200 wppm Polyox solution indicate that Polyox is as effective as Separan at $25^{\circ} \mathrm{C}$. It is, however, not effective at all at $87.8^{\circ} \mathrm{C}$. This suggests that the polymeric chains thermally break down at DH temperatures. Furthermore, it has been observed that Polyox comes out of aqueous solution at approximately $98^{\circ} \mathrm{C}$ [33].

In Fig. 4, experimental data for the 200 wppm Separan solution are compared with the screening data for one of the cationic surfactant systems that were tested at the Ohio State University (OSU) [34]. The Reynolds number in Fig. 4 is based on water viscosity. The surfactant 


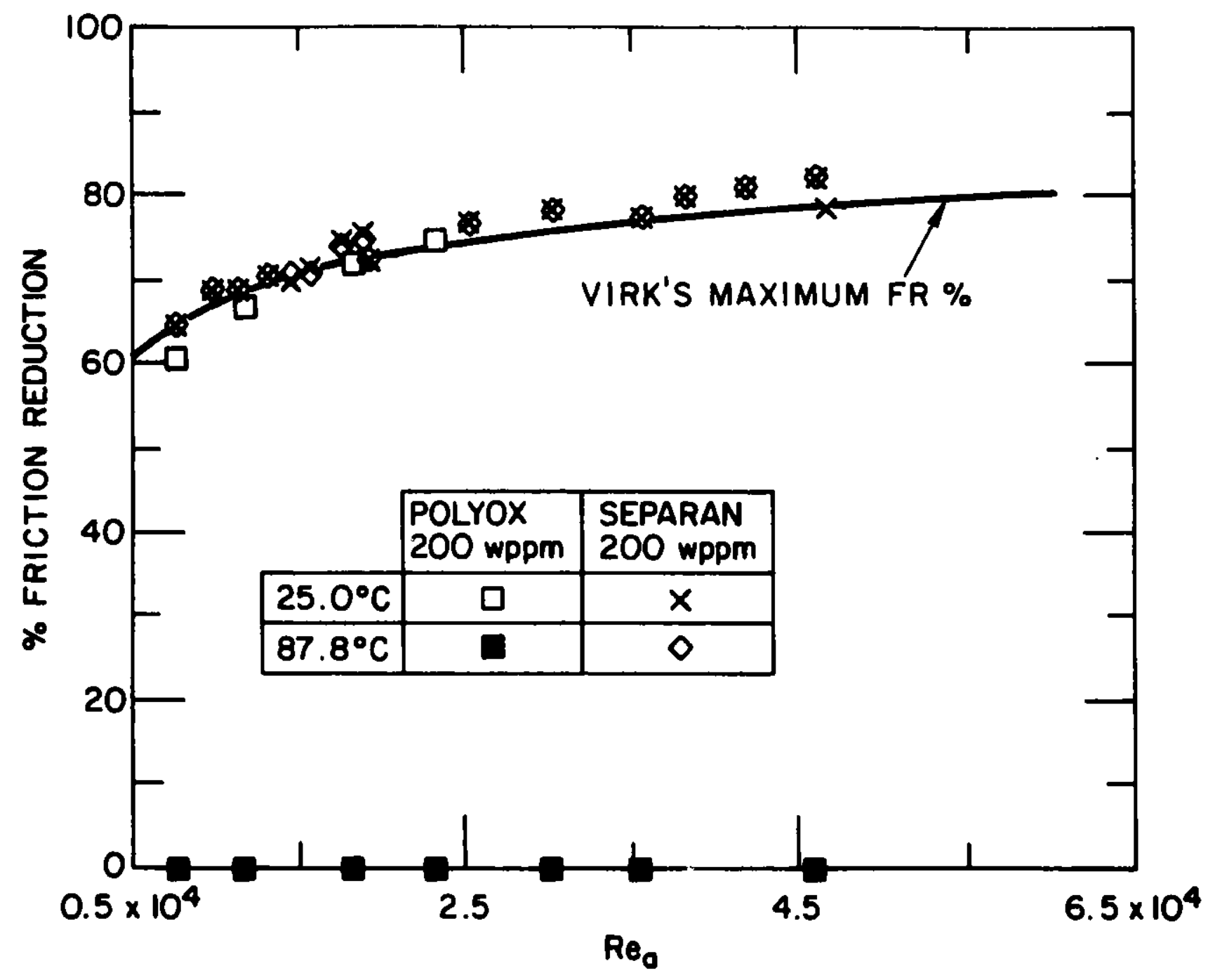

Fig. 3. Percent Friction Reduction vs. Reynolds Number for Polyox and Separan.

Reynolds number in Fig. 4 is based on water viscosity. The surfactant system is Kemamine Q-2983C (2000 wppm erucyl trimethylammonium chloride) complexed with 2000 wppm sodium salicylate. Both Separan AP-273 and Kemamine Q-2983C are good friction-reducing additives at DH temperatures, with friction reductions of $>60 \%$. It is interesting to note that Separan remains effective at low temperatures. This suggests that Separan is a good candidate for DH applications. In contrast, the surfactant system is not very effective at even $50^{\circ} \mathrm{C}$; its friction-reducing ability is limited to a much narrower range of temperature than that of Separan. This comparison shows that Separan has a slight edge over the surfactant screened at OSU, However, this is not a final comparison. Additional information such as longevity/stability and costs of these additives as 


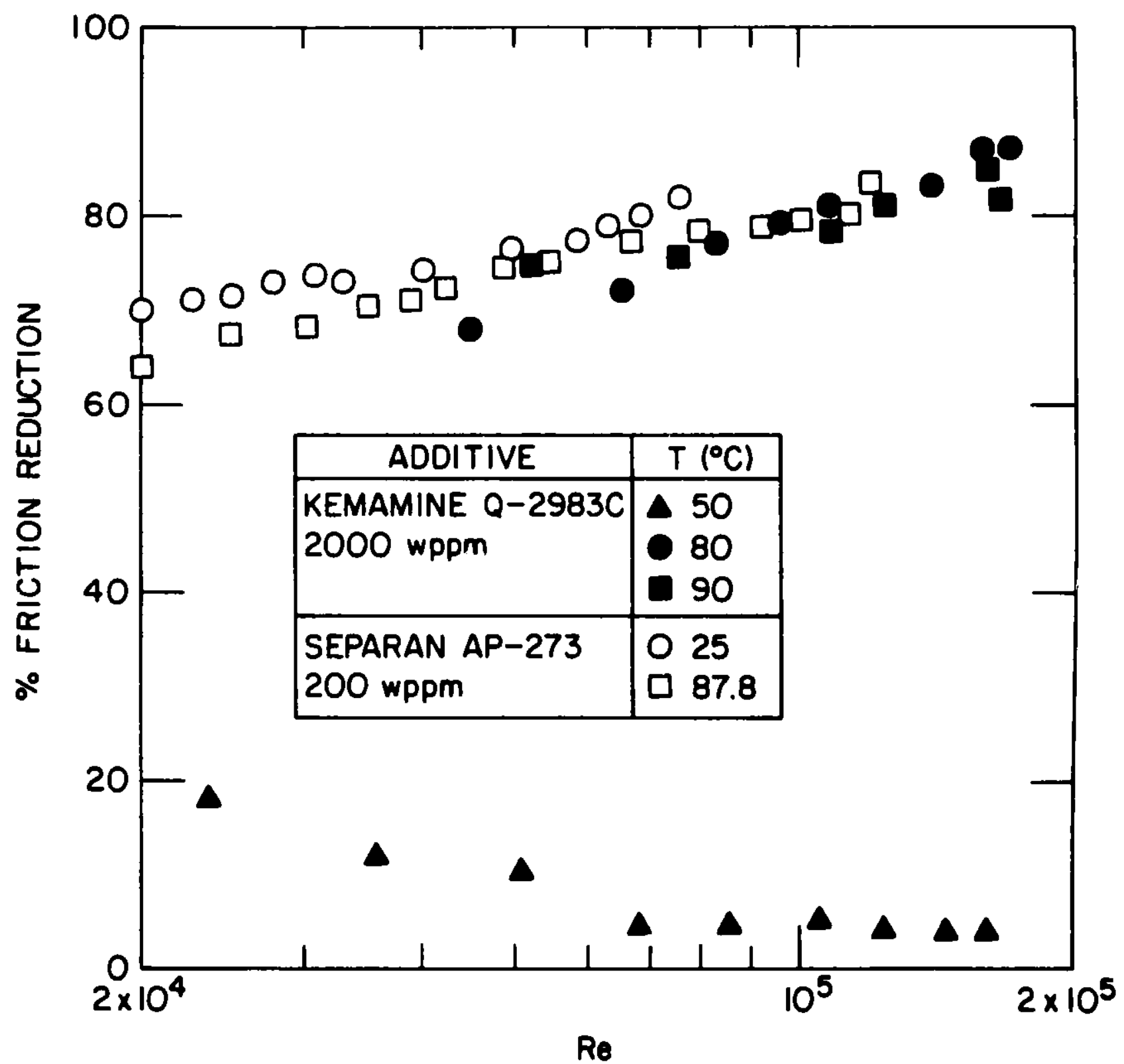

Fig. 4. Comparison of Percent Friction Reduction for Separan with That for Surfactant.

well as the impact of contaminants on friction reduction and longevity/ stability must be considered.

\subsection{Degradation Tests}

\subsubsection{Calibration of the Degradation Test Loop}

The friction-reducing additive degradation test loop was calibrated to validate the experimental procedures and data reduction 
formulas used. Calibration runs were conducted with pure water at $25^{\circ} \mathrm{C}$ and experimental friction and heat transfer coefficients were obtained for both hydrodynamically and thermally fully developed turbulent flow in the test sections.

The measured pure-water friction factors are presented as a function of Reynolds number in Fig. 5. The correlations of Von Karman and Blasius for flow of Newtonian fluids in a circular pipe over the range of Reynolds numbers between about 8000 and 45000 are in good agreement with the experimental data.

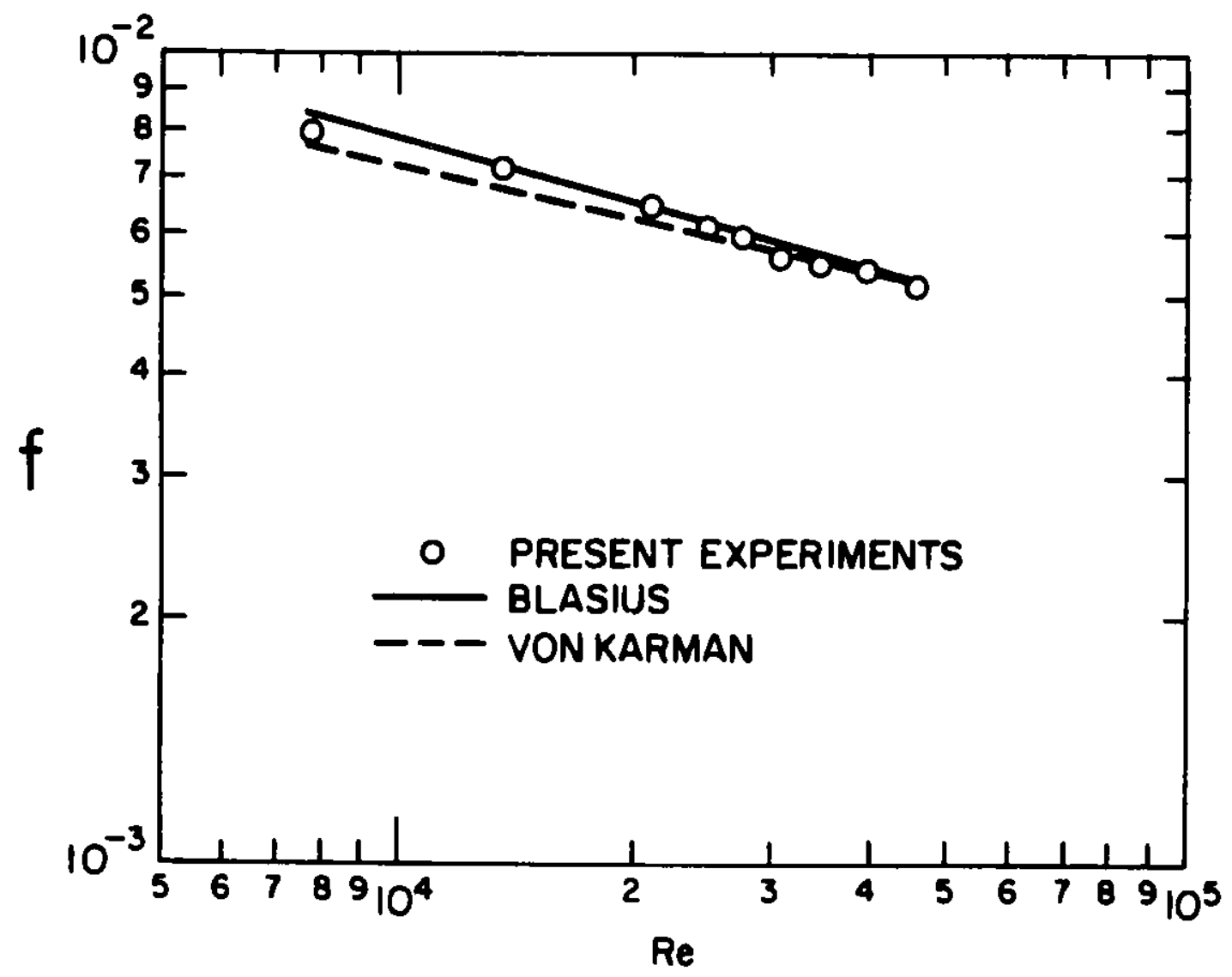

Fig. 5. Fanning Friction Factor vs. Reynolds Number for Water. 
The experimental heat transfer coefficients for pure water are shown in terms of the Nusselt number and Reynolds number in Fig. 6, together with the predictions from the Dittus and Boelter correlation given by $\mathrm{Eq} .(3.28)$. The experimental heat transfer values show very good agreement (within approximately 7\%) with the values predicted by the correlation of Dittus and Boelter. The heat transfer coefficients will be even more accurate for the polymer solutions than they are for water because the bulk-wall temperature difference is larger for the polymer solut:ons than for water, so thermocouple errors are less important for the polymer solutions.

\subsubsection{Degradation Tests with Separan Solution}

A 76-kg (167.0-lb) quantity of 200-wppm Separan AP-273 solution in deionized water was circulated in the degradation test loop at

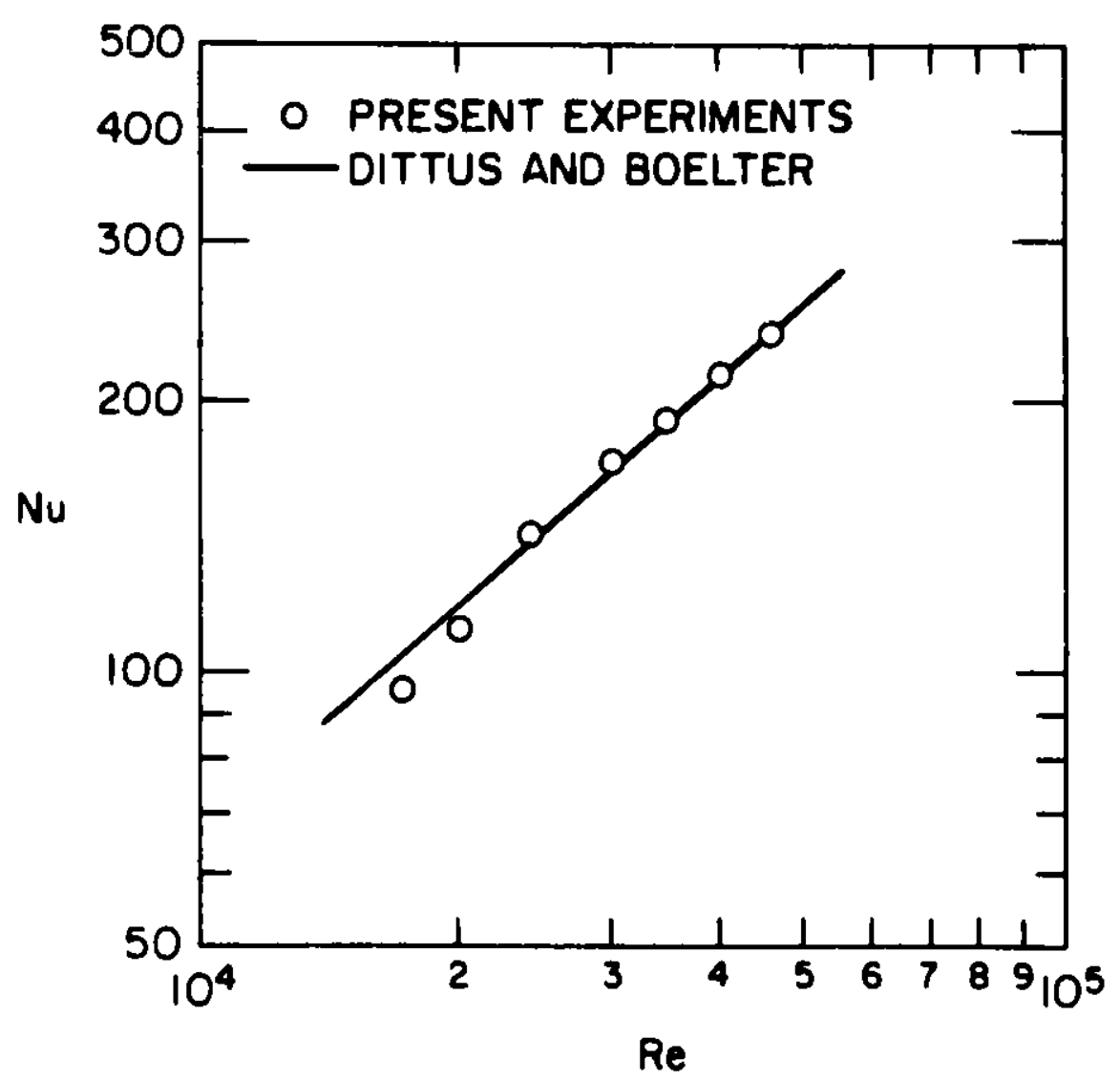

Fig. 6. Nusselt Number vs. Reynolds Number for Water. 
a constant flow rate of $9.53 \mathrm{~kg} / \mathrm{min}(21 \mathrm{lb} / \mathrm{min})$ for a period of 730 hours at room temperature (about $25.0^{\circ} \mathrm{C}$ ) in order to provide baseline degradation data for the high-temperature degradation tests at $87.8^{\circ} \mathrm{C}$. The shear level corresponding to the fixed circulation rate of $9.53 \mathrm{~kg} / \mathrm{min}$ is greater than the wall shear stress conditions encountered in a typical DHC system. The pressure drop and overall heat transfer coefficient are shown as a function of hours of shear in Fig. 7, and percent friction and heat transfer reductions compared with water data are given in Fig. 8.

During the first elght hours of circulation, the pressure drop decreased from the initial value of $29.6 \mathrm{kPa}$ (4.3 psi) to a minimum of $23.4 \mathrm{kPa}(3.4 \mathrm{psi})$. This may have been due to further mixing within the Separan solution. After reaching this minimum point, the pressure drop gradually increased, arriving at a plateau value of $49.0 \mathrm{kPa}(7.1 \mathrm{psi})$ at 240 hours of shear. From 240 to 730 hours of shear, the pressure drop

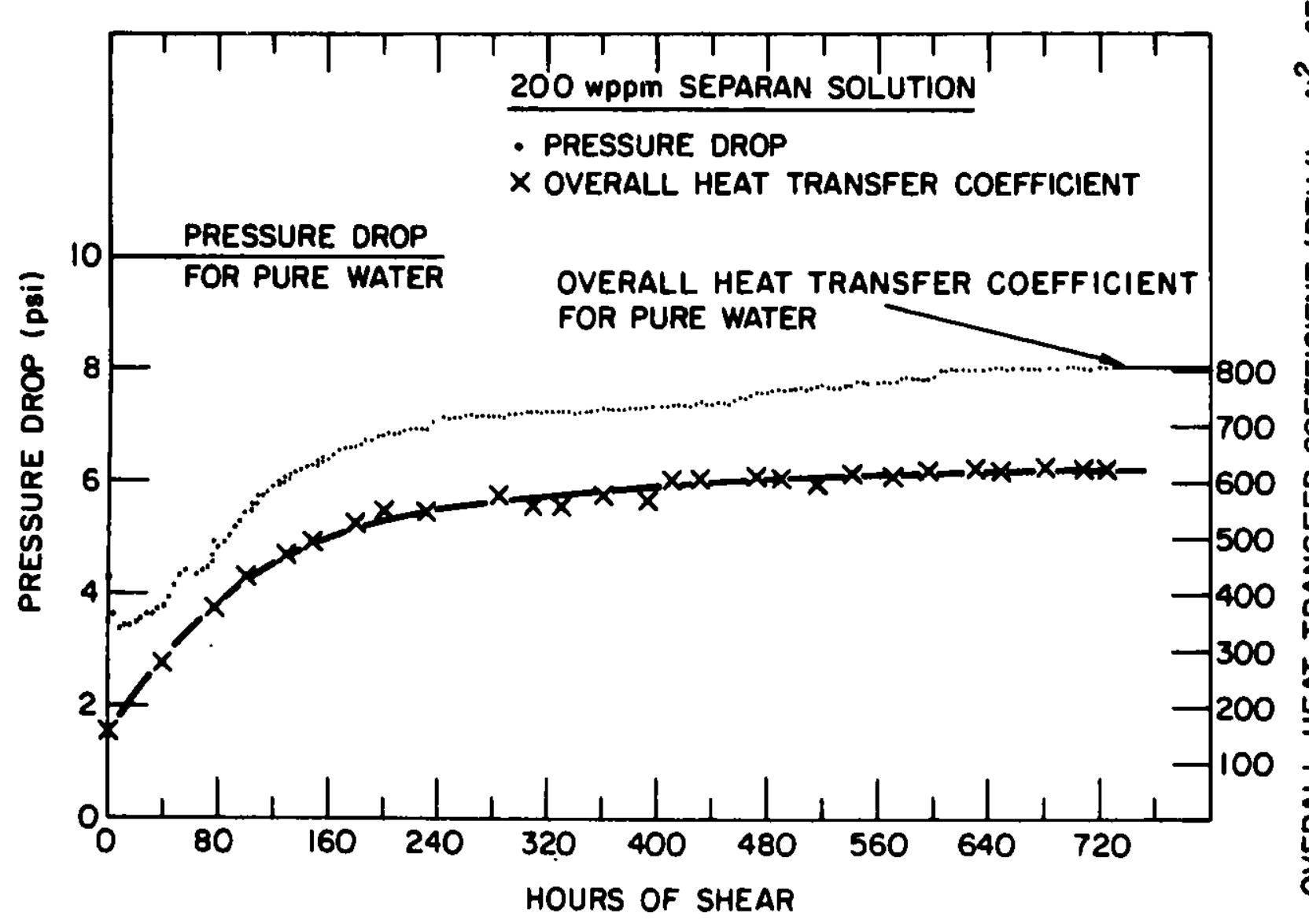

Fig. 7. Pressure Drop and Overall Heat Transfer Coefficient as a Function of Circulation Time for 200 wppm Separan Solution at $25^{\circ} \mathrm{C}$. 


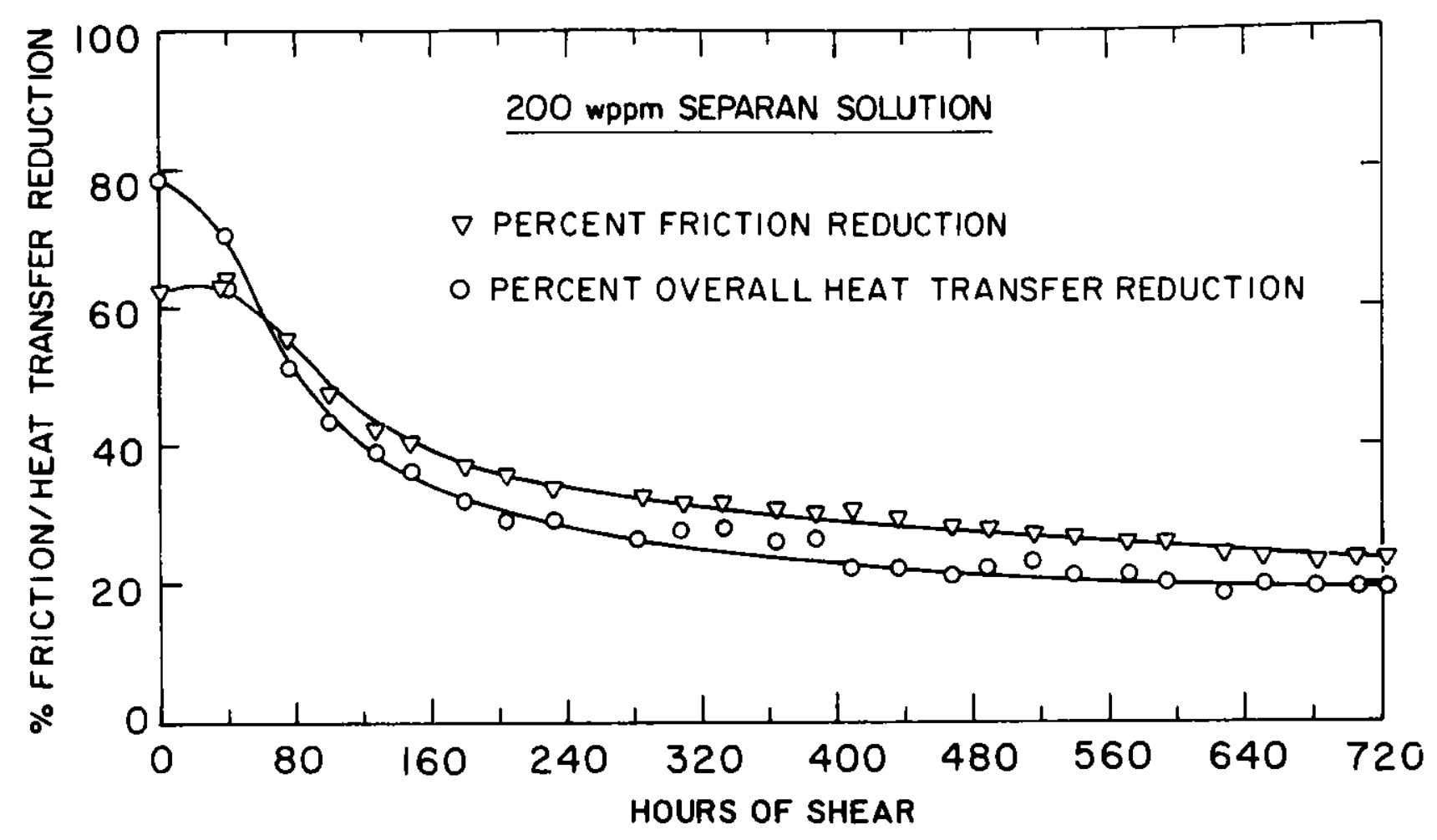

Fig. 8. Percent Friction/Heat Transfer Reduction Relative to Pure Water as a Function of Circulation Time for 200 wppm Separan Solution at $25^{\circ} \mathrm{C}$.

value changed very slowly from 49.0 to $55.8 \mathrm{kPa}(7.1$ to $8.1 \mathrm{psi})$. Even at 730 hours of shear, the pressure drop data represented about $25 \%$ friction reduction relative to pure water, as shown in Fig. 8 . This is an important finding because a friction reduction of even $10 \%$ in DHC systems could result in large annual cost savings. Figure 7 demonstrates that the overall heat transfer coefficient changed rather rapidly from its initial value of $936.4 \mathrm{~W} / \mathrm{m}^{2} \mathrm{~K}\left(164.9 \mathrm{Btu} / \mathrm{hr}-\mathrm{ft} \mathrm{t}^{2}{ }^{\circ} \mathrm{F}\right)$ and reached a plateau value of $3,235 \mathrm{~W} / \mathrm{m}^{2} \mathrm{~K}\left(569.7 \mathrm{Btu} / \mathrm{hr}-\mathrm{ft}^{2}-{ }^{\circ} \mathrm{F}\right)$ at 240 hours of shear. From 240 to 730 hours of shear, it increased gradually, reaching the value of $3547 \mathrm{~W} / \mathrm{m}^{2} \mathrm{~K}$ $\left(624.6 \mathrm{Btu} / \mathrm{hr}-\mathrm{ft}^{2}-{ }^{\circ} \mathrm{F}\right)$ at 730 hours of shear. This plateau corresponds to about $22 \%$ heat transfer reduction relative to pure water. As shown in Fig. 8 , the friction reduction is accompanied by heat transfer reduction. Initially, the percent heat transfer reduction (i.e., 78\%) was larger than the percent friction reduction (about 65\%). However, at 60 hours of shear, the percent friction reduction was about the same as the percent heat 
transfer reduction. After this point, the former was found to be consistently larger than the latter by about $5 \%$, as seen in Fig. 8 .

Viscosity measurements were conducted with a capillary tube with internal diameter of $0.1022 \mathrm{~cm}$ and length of $60.484 \mathrm{~cm}$. Three samples of aqueous 200 wppm Separan solution collected at three different times during the degradation test $(0,147$, and 730 hours of shear) were tested. Figure 9 shows the measured apparent viscosity of the solution samples in the shear rate range of 1500 to $4200 \mathrm{~s}^{-1}$. The Separan solutions exhibit strong nonlinear viscosity functions. Viscosities of sheardegraded solutions, particularly those degraded at low shear rates, were found to be lower than those of fresh solutions. The decrease in viscosity

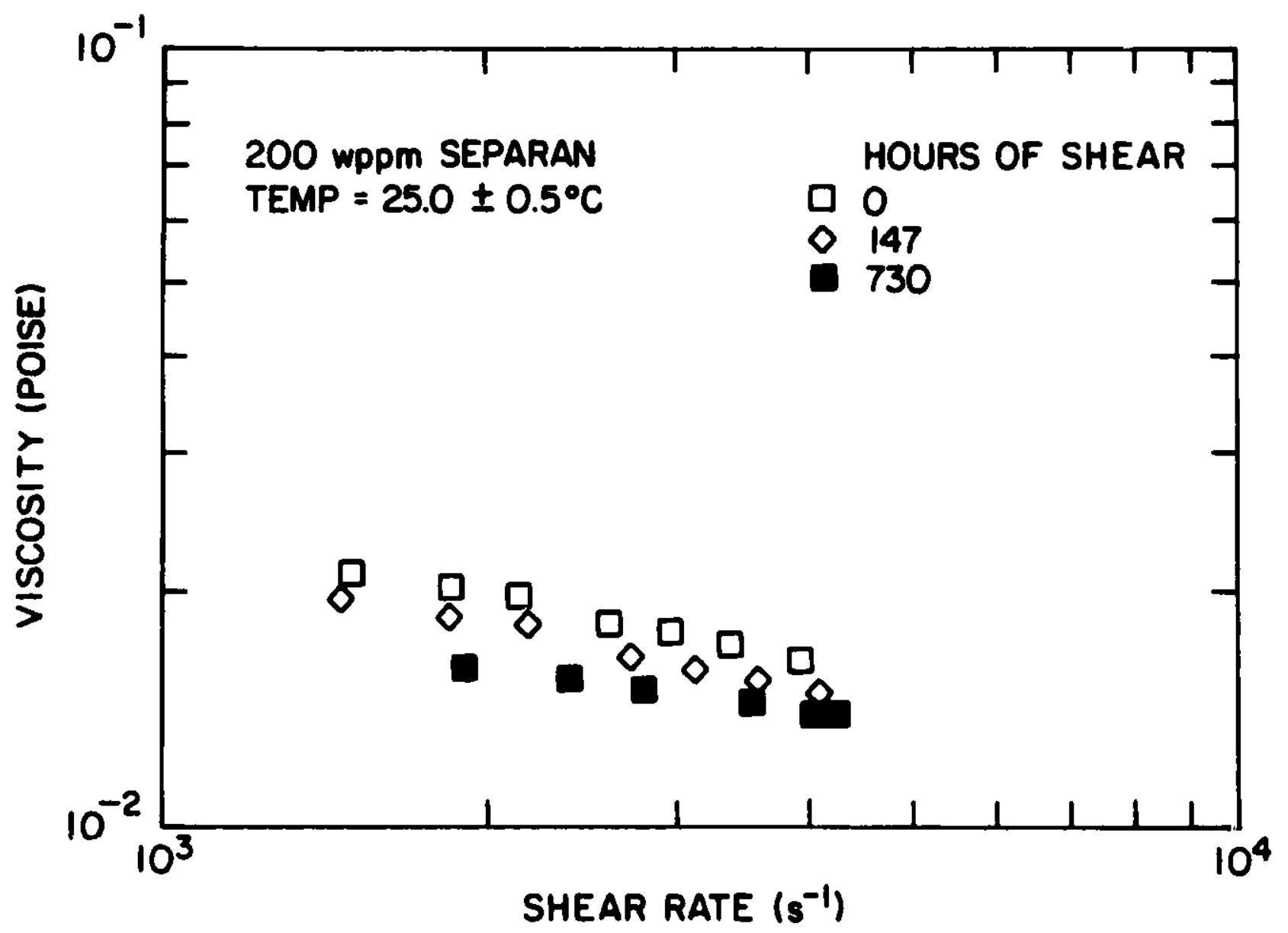

Fig. 9. Apparent Viscosities of 200 wppm Separan Solution Samples Collected at Different Hours of Shear. 
at low shear rates is an indication of a decrease in the elastic force, which is responsible for the friction reduction, as the polymer solution is degraded.

Degradation runs were repeated with 200 wppm Separan solution at $87.8^{\circ} \mathrm{C}$. A stainless steel heater was used in the test fluid tank to achieve the test fluid temperature. The fluid was circulated in the degradation test loop for about 90 hours. High-temperature pressure drop results are shown in Fig. 10, together with the pressure drop data at room temperature. The turbulent pressure drop at $87.8^{\circ} \mathrm{C}$ increased rapidly

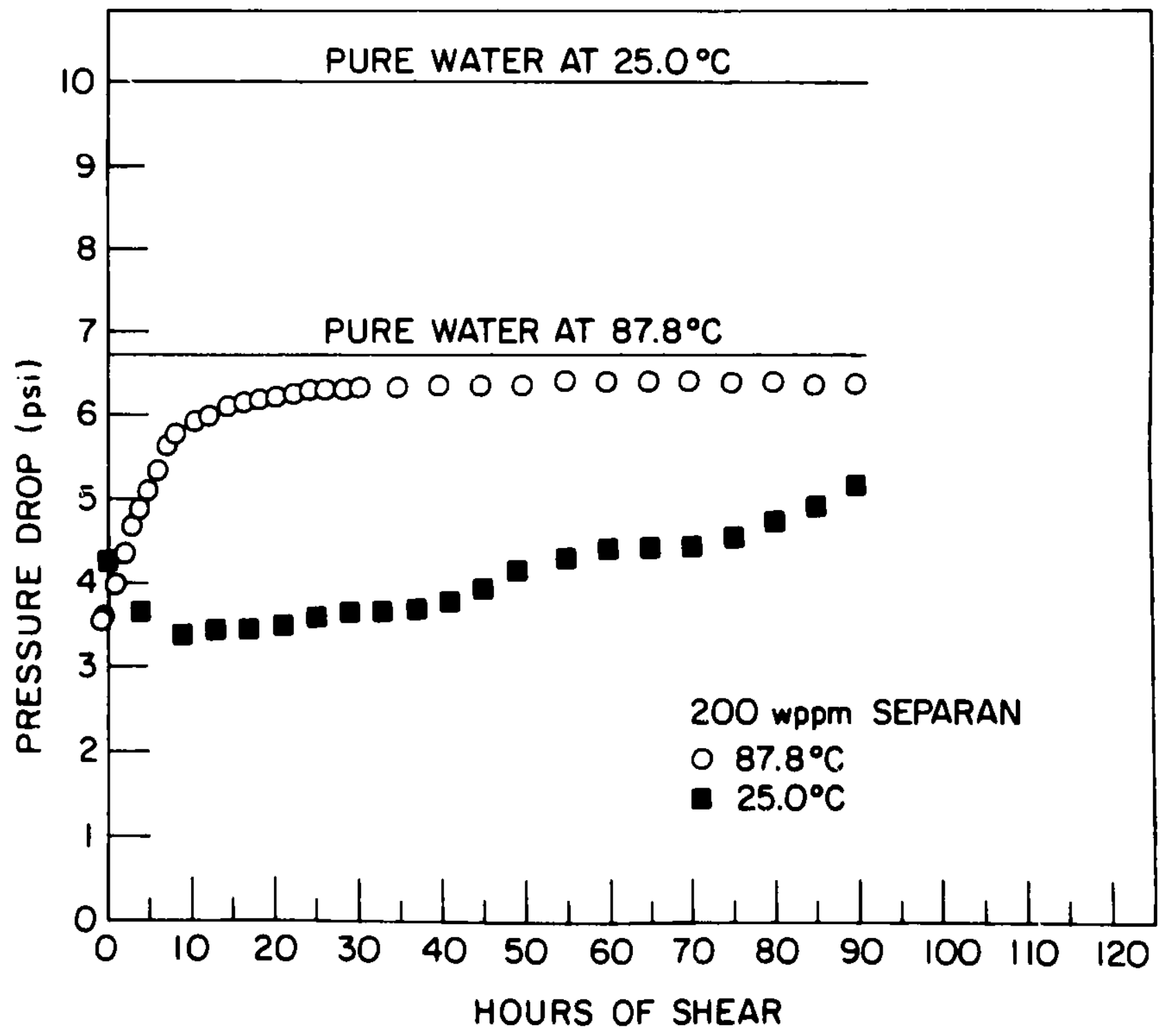

Fig. 10. The Effect of Temperature on Pressure Drop as a Function of Circulation Time for 200 wppm Separan Solution. 
for the first 24 hours of circulation and then remained at an asymptotic value for the rest of the testing period. The heat transfer behavior was similar to that of pressure drop, confirming that pressure drop reduction is always accompanied by heat transfer reduction.

It is interesting to note the effect of temperature on the degradation rate of 200 wppm Separan solution. It appears that the polymer bonds are more easily ruptured at higher temperature. Therefore, the effect of degradation on pressure drop and heat transfer is more pronounced at $87.8^{\circ} \mathrm{C}$ than at room temperature, as shown in Fig. 10. At high temperature, the degree of friction reduction decreased from approximately $46 \%$ with fresh solution to the asymptotic value of about $6 \%$ with sheardegraded dilute Separan solution. Although spectacular friction reductions, say $50 \%$ or so, were not achieved with degraded 200 wppm Separan solution, Separan appears to be attractive as a potential candidate because there have been some reports that the degree of friction reduction can be increased in degrading solutions when the Separan concentration is increased [35]. Tests will be conducted to see whether the plateau value can increase with additive concentation. If this is the case, Separan will be a promising candidate for use in DH systems. Further experimental work is required to verify this conjecture.

The reduction in heat transfer with the use of frictionreducing additives should be considered very carefully because DHC systems contain a number of heat exchangers at which heat transfer takes place. For DHC systems that use a large number of liquid-to-air heat exchangers, the reduction of the liquid-to-wall heat transfer by additives has only a minor impact (of the order of a few percent reduction) on the overall heat exchanger performance. This is because the overall heat transfer coefficient consisting of the liquid-to-wall, wall, and wall-to-air resistances is dominated by the wall-to-air component. Even for liquid-toliquid heat exchangers, this profected reduction of heat transfer based on fully developed flow data may not be as great in actual heat exchangers because the heat transfer would most likely be occurring under nonfully developed flow conditions. Because heat transfer performance data from actual heat exchangers with friction-reducing additive solutions is nonexistent, this is a high-priority research area to be explored at ANL. 
It should be noted that the reduction in heat transfer would have a beneficial effect in reducing heat losses to the ambient from long transmissiori piping systems.

Also, comparisons of Separan with other additives must be evaluated in terms of economics as well as friction-reducing ability and longevity. For example, the surfactant additives currently being tested are considerably more expensive than Separan, and they must be used at a factor of 10 higher concentration and in conjunction with other conditioning chemicals. Separan, supplemented by periodic injections of make-up additive, could be a feasible alternative to more costly, more robust additives. Furthermore, the cationic surfactants are known to be very sensitive to chemical contaminants and water chemistry, and difficulty may be encountered under prototypic conditions. In this regard, fiber friction-reducing additives to be tested at ANL appear promising.

Recently, the impact of advanced energy transmission fluids on DHC systems was assessed [36]. This assessment represents an effort to develop benefit guidelines for friction-reducing additives. However, it should be pointed out that the assessment was based on the maximum friction reduction level, which is possible only if the additives undergo no degradation at all. These benefit studies will be reevaluated with actual friction reduction level and longevity data generated from degradation tests as promising additives are identified and testing is completed.

\subsubsection{Degradation Tests with Polyox Solution}

A 76-kg quantity of 200-wppm Polyox WSR-301 solution was prepared and circulated at a constant flow rate of $9.53 \mathrm{~kg} / \mathrm{min}$ in the same flow loop at $25.0^{\circ} \mathrm{C}$ for 22 hours. Figure 11 shows pressure drop and heat transfer coefficients as a function of time. The pressure drop and heat transfer data were replotted in,Fig. 12 in terms of the percent friction and heat transfer reduction.

Both pressure drop and heat transfer values increased rapidly (compared with those of Separan solution) as soon as circulation started, reaching their respective Newtonian values at about 18 hours of 


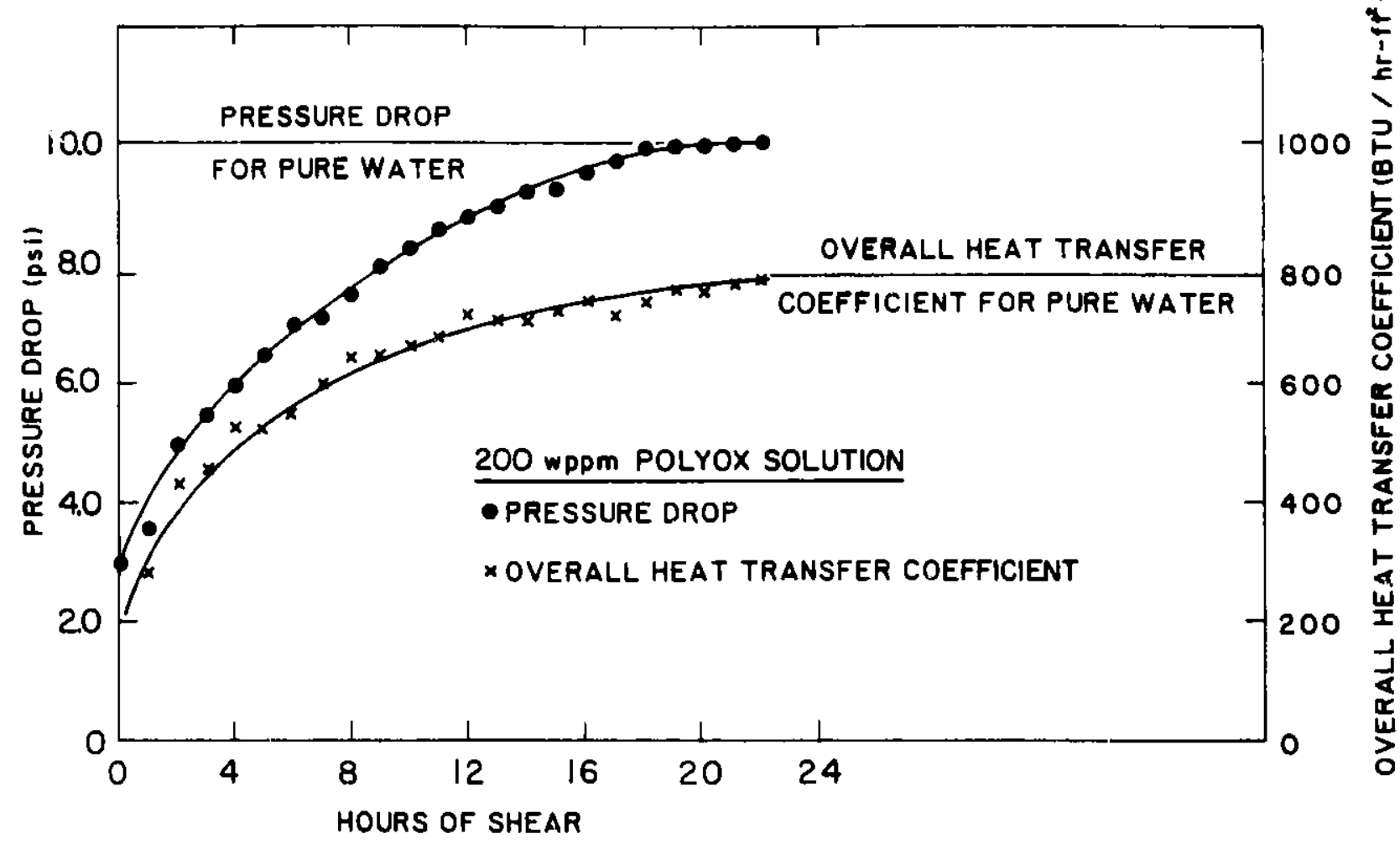

Fig. 11. Pressure Drop and Overall Heat Transfer Coefficient as a Function of Circulation Time for 200 wppm Polyox Solution at $25^{\circ} \mathrm{C}$.

shear. The 200 wppm Separan solution took about 240 hours, or more than one order of magnitude longer, to reach asymptotic values (Fig. 7). Clearly, Polyox solution was much more susceptible to mechanical degradation than Separan solution at the same concentration. As shown in Fig. 12, the percent friction reduction was consistently larger than the percent heat transfer reduction, as was the case with Separan solution after 60 hours of shear.

Because of the extreme sensitivity of Polyox solution to mechanical degradation, even at room temperature, further degradation tests at higher temperature were not conducted. Thus, Polyox is ruled out for further studies. This clearly demonstrates that, although some additives show significant friction reduction in the preliminary capillary tube screening tests, they must undergo long-term degradation tests in the closed recirculatory test loop to assess their useful lifetime. 


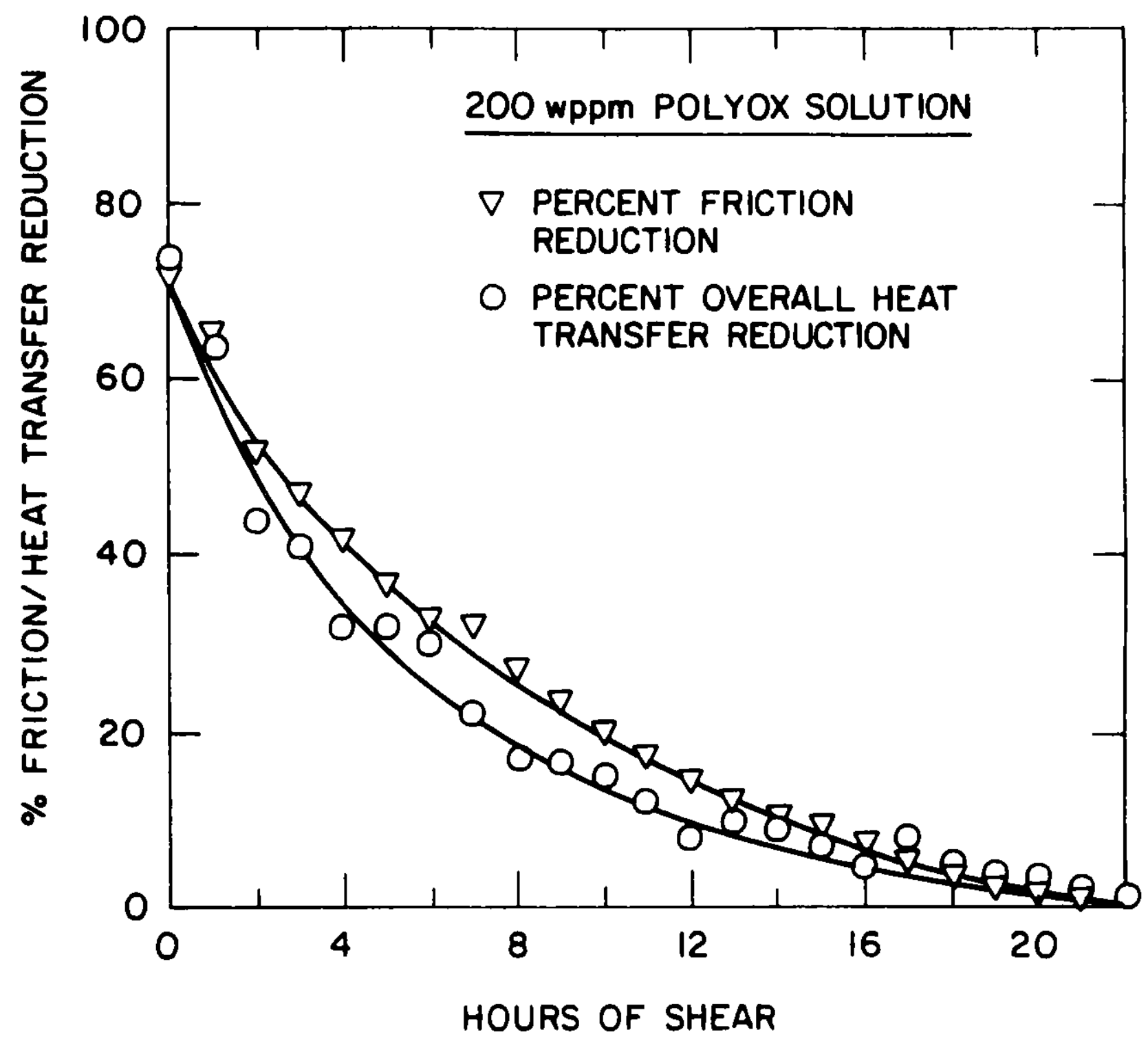

Fig. 12. Percent Friction/Heat Transfer Reduction Relative to Pure Water as a Function of Circulation Time for 200 wppm Polyox Solution at $25^{\circ} \mathrm{C}$.

\subsection{Conclusions}

In an attempt to develop advanced non-Newtonian energy transmission fluids that would yield friction reduction and have a reasonable lifetime at $\mathrm{DH}$ temperatures, two high-molecular-weight linear-polymer solutions have been tested in this study. Screening and degradation tests have been conducted with aqueous 200 wppm Separan and Polyox solutions. The results to date can be summarized as follows: 
1. Screening tests show that significant friction reduction (over $60 \%$ ) can be achieved with a 200 wppm Separan solution at temperatures of $25.0^{\circ} \mathrm{C}$ and $87.8^{\circ} \mathrm{C}$. A 200 wppm Polyox solution is as effective as Separan solution at room temperature. However, Polyox completely loses its effectiveness at high temperature.

2. Long-term degradation tests with 200 wppm Separan solution for 730 hours at room temperature and 90 hours at $87.8^{\circ} \mathrm{C}$ show that - A significant feature of the pressure drop and neat transfer behavior as a function of time is the existence of a plateau, which suggests that no further degradation occurs after the initial degradation period. The initial degradation period is shorter at higher temperature. The degree of friction reduction with shear-degraded dilute Separan solution is $25 \%$ at room temperature and $6 \%$ at high temperature.

- Heat transfer reduction always accompanies friction reduction regardless of the hours of shear. In general, the percent friction reduction was slightly larger than the percent heat transfer reduction.

3. Degradation tests with 200 wppm Polyox solution at room temperature show that although Polyox is as effective as Separan in the screening tests, Polyox is much more susceptible to mechanical degradation. Pressure drop and heat transfer reached their Newtonian values within one day of circulation. The degradation rate of Polyox is much higher than that of Separan. This indicates that Polyox is not suitable at all for DHC applications.

\subsection{Future Activities}

In order to confirm that Separan is indeed a promising candidate for DHC applications, further study is required, particularly to investigate the possibility of enhancing friction reduction levels with shear-degraded solutions by increasing the Separan concentrations. Additionally, ail candidate additives must be evaluated for compatibility with various water contaminants and water treatment chemicals. In addition, degradation 
testing of Separan solution is needed at DC temperatures, because the room temperature test results strongly suggest that Separan is a good candidate for DC applications. Also, methods of controlling and minimizing the degradation process are an important technical issue that should be addressed in the near future. Techniques such as injection of makeup additive will be explored.

The experimental studies conducted on heat transfer show that heat transfer reduction accompanies the desired friction reduction. It is important to assess the impact of this heat transfer reduction on the overall performance of actual heat exchange equipment. Because no data are available on heat transfer in commonly used heat exchangers during operation with friction-reducing solutions, testing will be conducted at ANL with several types of heat exchangers.

Since only linear polymers were tested to date, other types of additives including Tenside, polyester fiber, glass fiber, and iron whisker filaments will be tested and reported in the next phase of the program.

Finally, in CY 1988, testing of the most promising additives in a large recirculatory flow loop will be initiated at ANL with temperatures ranging from $104^{\circ} \mathrm{C}$ to $4^{\circ} \mathrm{C}$, flows of up to $2000 \mathrm{gal} / \mathrm{min}$, and pipes up to 6 in. in diameter. This loop also has steam-heated and chilled-watercooled shell-and-tube heat exchangers to allow assessments of heat transfer. The facility is computer controlled to allow simulation of flow and temperature changes encountered with prototypic DHC systems.

\section{Acknowledgments}

Support by the U.S. Department of Energy, Office of Buildings and Community Systems, is gratefully acknowledged. The authors would like to express special thanks to DOE program manager Jake Kaminsky for his special interest, guidance, and continued support of this work. We are indebted to Ed U'Hare and Paul Fu for their technical assistance. Thanks are also due to Cathy Bertino for typing of the report. 


\section{$\underline{\text { References }}$}

1. Kasza, K. E., Choi, U. S., and Kaminsky, J., "Reducing the High Costs of District Heating and Cooling," Specif. Eng., Vol. 56 (4), pp. 3842, October 1986.

2. Kasza, K. E. and Chen, M. M., Development of Enhanced Heat Transfer/ Transport/Storage Slurries for Thermal System Improvement, Argonne National Laboratory Report ANL-82-50, June 1982.

3. Kasza, K. E. and Chen, M. M., "Improvement of the Performance of Solar Energy or Waste Heat Utilization Systems by Using Phase Change Slurry as an Enhanced Heat-Transfer Storage Fluid," ASME Trans.; J. Sol. Energy Eng., Vol. 107, pp. 229-236, August 1985.

4. Toms, B. A., "Some Observations on the Flow of Linear Polymer Solutions Through Straight Tubes at Large Reynolds Numbers," in Proc. 1st Intl. Congress on Rheology, Vol. 2, pp. 135-141, North-Holland Publishing Co., Amsterdam, 1948.

5. Skelland, A. H. P., Non-Newtonian Flow and Heat Transfer, John Wiley, New York, 1967.

6. Middleman, S., The Flow of High Polymers, Interscience, New York, 1968.

7. Bird, R. B., Armstrong, R. C., and Hassager, 0., Dynamics of Polymer Liquids, Vol. 1, Fluid Mechanics, John Wiley, New York, 1977.

8. Schowalter, W., Mechanics of Non-Newtonian Fluids, Pergamon, Oxford, 1977.

9. Hoyt, J. W., "The Effect of Additives on Fluid Friction," Trans. ASME J. Basic Eng., Vol. 94D, pp. 258-285, June 1972.

10. Metzner, A. B., "Heat Transfer in Non-Newtonian Fluids," in Advances in Heat Transfer, Vol. 2, pp. 357-397, Academic Press, New York, 1965.

11. Virk, P. S., "Drag Reduction Fundamentals," AIChE J., Vol. 21, pp. 625-656, 1975.

12. Dimant, Y. and Poreh, M., "Heat Transfer in Flows with Drag Reduction," in Advances in Heat Transfer, Vol. 12, pp. 77-113, Academic Press, New York, 1976.

13. White, A. and Hemmings, J. A. G., Drag Reduction by Additives - Review and Bibliography, BHRA Fluid Engineering, Cranfield, England, 1976.

14. Winter, H. H., "Viscous Dissipation in Shear Flows of Molten Polymer," In Advances in Heat Transfer, Vol. 13, pp. 205-267, Academic Press, New York, 1977. 
15. Shenoy, A. V. and Mashelkar, R. A., "Thermal Convection in NonNewtonian Fluids," in Advances in Heat Transfer, Vol. 15, pp. 143-225, Academic Press, New York, 1982.

16. Cho, Y. I. and Hartnett, J. P., "Non-Newtonian Eluids in Circular Pipe Flow," in Advances in Heat Transfer, Vol. 15, pp. 59-141, Academic Press, New York, 1982.

17. Cho, Y. I. and Harnett, J. P., "Non-Newtonian Fluids", in Handbook of Heat Transfer Applications, Chapter 2, McGraw-Hill, New York, 1985.

18. Kwack, E. Y., Cho, Y. I., and Hartnett, J. P., "Effect of Weissenberg Number on Turbulent Heat Transfer of Aqueous Polyacrylamide Solutions," in Proc. 7th Intl. Heat Transfer Conference, Vol. 3, pp. 63-68, Hemisphere Publishing Co., Washington, D.C., 1982.

19. Kwack, E. Y. and Hartnett, J. P., "Effect of Solvent Chemistry on Critical Weissenberg Numbers," Intl. J. Heat Mass Transfer, Vol. 25, pp. 1445-1531, 1982 .

20. Powell, R. E. and Eyring, H., "Mechanism for Relaxation Theory of Viscosity," Nature, Vol. 154, pp. 427-428, 1944.

21. McIwrath, J. C., "Cortinuous Degradation of Polymer Solutions in Simulated Pipe Flow," in Proc. Intl. Conference on Drag Reduction, Paper C3, BHRA Fluid Engineering, Cranfield, England, 1974.

22. Block, H., Moran, A. N., and Walker, S. M., "The Reduction of Turbulent Drag and the Degradation of Polystyrene in Toluene," in Proc. Intl. Conference on Drag Reduction, Paper C4, BHRA Fluid Engineering, Cranfield, England, 1974.

23. Sellin, R. H. J., "Experiments with Polymer Additives in a Long Pipe Line," in Proc. Intl. Conference on Drag Reduction, Paper G2, BHRA Fluid Engineering, Cranfield, England, 1974.

24. Tung, T. T., Ng, K. S., and Hartnett, J. P., "Influence of Rheological Property Changes on Friction and Convective Heat Transfer in a Viscoelastic Polyacrylamide Solution," in Proc. 6th Intl. Heat Transfer Conference, Vol. 5, pp. 329-333, Hemisphere Publishing Co., Washington, D.C., 1978.

25. $\mathrm{Ng}, \mathrm{K} . \mathrm{S}$. and Hartnett, J. P., "Effects of Mechani zal Degradation on Pressure Drop and Heat Transfer Performance of Polyacrylamide Solutions in Tubulent Pipe Flow," in Studies in Heat Transfer, pp. 297-307, McGraw-Hill, New York, 1979.

26. Carreau, P. J., "Rheological Equations for Molecular Network Theories," Trans. Soc. Rheol., Vol. 16(1), pp. 99-127, 1972.

27. Bird, R. B. and Deaguiar, J. R., "An Encapsulated Dumbbell Model for Concentrated Polymer Solutions and Melts," J. Non-Newtonian Fluid Mech., Vol. 13, pp. 149-160, 1983. 
28. Kays, W. M. and Crawford, M. E., Convective Heat and Mass Transfer, 2nd Ed., McGraw-Hill, New York, 1980.

29. Reynolds, A. J., Turbulent Flows in Engineering, John Wiley, London, 1974.

30. Virk, P. S., Mickely, H. S., and Smith, K. A., "The Ultimate Asymptote and Mean Flow Structure in Toms' Phenomenon," Trans. ASME, Vol. 37, p. $488,1970$.

31. Ng, K. S., Cho, Y. I., and Hartnett, J. P., "Heat Transfer Performance of Concentrated Polyethylene Oxide and Polyacrylamide Solutions," AIChE Symp. Ser., Vol. 76(199), pp. 250-256, 1980.

32. Dittus, F. W. and Boelter, L. M. K., "Heat Transfer in Automobile Radiators of the Tubular Type," Univ. Calif. Berkeley Publ. Eng., Vol. 2(13), p. 443, 1930.

33. Hartnett, J. P. and Hu, R. Y. Z., "Role of Rheology in Boiling Studies of Viscoelastic Liquids," Int. Comm. Heat Mass Transfer, Vol. 13, pp. 627-637, 1986 .

34. Chou, L-C., Christensen, R. N., and Zakin, J. L., "The Use of Cationic Surfactant Additives to Reduce Transmission Pumping Costs in District Heating Systems," presented at the Annual Conference of the International District Heating and Cooling Association, Baltimore, PA, June 1987 .

35. Darby, R., "A Generalized Correlation for Friction Loss in Drag Reducing Polymer Solutions," in Encyclopedia of Fluid Mechanics, Chapter 33, Gulf Publ. Co., Houston, 1986.

36. Kasza, K. E. and Chen, M. M., Assessment of Impact of Advanced Energy Transmission Fluids on District Heating and Cooling Systems (Phase I), Argonne National Laboratory Report ANL-87-21, 1987. 
Distribution for ANL-87-49

Interna1:
H. Drucker
W. Shack
A. Wolsky
F. Weeks
D. Raske
P. Kier
W. Schertz
A. Rapt is
J. Tschanz
K. Kasza (5)
D. Kupperman
E. Stefanski
S. Choi (25)
S. Sheen
ANL Patent Dept.
K. Liu
$Y$. Chang
J. Oras
J. Karvelas
T. Kuzay
A. Thomas
H. Stevens
ANL Contract File
C. Till
ANL Libraries (2)
TIS Files (3)

\section{External:}

DOE-TIC, for distribution per UC-95D and UC-231 (233)

J. Millhone, DOE

J. Holmes, DOE

R. Jones, DOE

J. Kaminsky, DOE

F. Collins, DOE

L. Delacroix, DOE

D. T. Goldman, DOE-CH

F. Herbaty, DOE-CH

P. Shewmon, Ohio State Univeristy 